\title{
Catalytic dehydration of ethanol over post-treated ZSM-5 zeolites
}

\author{
Hongchuan Xin ${ }^{\mathrm{a}, 1}$, Xiangping $\mathrm{Li}^{\mathrm{a}, 1}$, Yuan Fang ${ }^{\mathrm{a}}$, Xianfeng $\mathrm{Yi}^{\mathrm{b}}$, Wenhui Hu ${ }^{\mathrm{a}}$, Yueying $\mathrm{Chu}^{\mathrm{b}}$, \\ Feng Zhang ${ }^{\mathrm{a}}$, Anmin Zheng ${ }^{\mathrm{b}, *}$, Hongpeng Zhang ${ }^{\mathrm{a}}$, Xuebing $\mathrm{Li}^{\mathrm{a}, *}$ \\ ${ }^{a}$ Key Laboratory of Biofuels, Qingdao Institute of Bioenergy and Bioprocess Technology, Chinese Academy of Sciences, Qingdao 266101, China \\ ${ }^{\mathrm{b}}$ Wuhan Center for Magnetic Resonance, State Key Laboratory of Magnetic Resonance and Atomic and Molecular Physics, Wuhan Institute of Physics and Mathematics, \\ Chinese Academy of Sciences, Wuhan 430071, China
}

\section{A R T I C L E I N F}

\section{Article history:}

Received 13 November 2013

Revised 4 February 2014

Accepted 7 February 2014

\section{Keywords:}

ZSM-5

Dehydration of ethanol

Ethylene

Desilication

Dealumination

Reaction mechanism

Theoretical calculation

\begin{abstract}
A B S T R A C T
Microporous ZSM-5 zeolite was post-treated by desilication with sodium hydroxide, dealumination with oxalic acid, or both of them in a sequential way to finely tune the zeolite catalysts with hierarchically porous structure and varying acidity. In the catalytic dehydration of ethanol, diethyl ether and ethylene were two main products competitively formed at $200^{\circ} \mathrm{C}$ and atmospheric pressure. The post-treated ZSM-5 catalysts could display stable ethanol conversion and ethylene selectivity within time-on-stream of around $12 \mathrm{~h}$. The correlation between the steady-state ethylene selectivity and the amount of weak acid sites from ammonia temperature-programmed desorption ( $\mathrm{NH}_{3}$-TPD) indicated that the weak acid sites facilitated the ethylene production during ethanol transformation under present reaction conditions. The reaction pathways for diethyl ether and ethylene formations from ethanol were investigated by theoretical calculation. Both the activation energies and natural charges of the transition states strongly supported that the selectivity for the diethyl ether tended to deteriorate with decreasing catalytic Brønsted acidity.
\end{abstract}

(c) 2014 Elsevier Inc. All rights reserved.

\section{Introduction}

The availability and low cost of a wide range of feedstocks (lignocellulosic materials) may offer opportunities for the biotechnological production of bioethanol worldwide [1]. Through the utilization of bioethanol as a chemical resource, it has received considerable industrial attention to provide an alternative route to convert ethanol to ethylene or higher hydrocarbons [2]. Ethylene is one of the largest volume chemical intermediates in the industry, which is driven by the polyethylene market [3]. Compared with the traditional process of petroleum to ethylene, the ethylene production from dehydration of ethanol is economically feasible with higher ethylene purity [4]. In order to make ethanol dehydration more industry-friendly, scientists and researchers have developed different catalysts to enhance ethylene yield and lower reaction temperature. The catalysts for acid-catalyzed alcohol dehydration can be classified as four categories [4]: phosphoric acids, oxides, zeolites, and heteropolyacids. Among the zeolite catalysts, ZSM-5 zeolite is most widely studied, due to its possibil-

\footnotetext{
* Corresponding authors.

E-mail addresses: zhenganm@wipm.ac.cn (A. Zheng), lixb@qibebt.ac.cn (X. Li).

1 These authors contributed equally to this paper.
}

ity of catalyzing the reaction at lower temperatures, which made it commercially valuable and promising [5].

Methanol to olefin (MTO) process has been well studied academically and industrially [6]. The reaction mechanism and intermediate species of MTO over acid sites of zeolites were thoroughly investigated by different characterization techniques [7]. The nanosheet ZSM-5 catalyst with comparable acidity and stability to conventional ZSM-5 could dramatically depress the deactivation during methanol-to-gasoline reaction [8]. Some work on the ethanol reaction has been investigated over the ZSM-5 zeolite. It was reported that the acid density of ZSM- 5 zeolites increased with decreasing $\mathrm{Si} / \mathrm{Al}$ atomic ratio, resulting in lower ethylene production under reaction condition of atmospheric pressure [9] or higher pressure [10]. The same trend was also found by another group that the ethylene selectivity was steadily increased with the $\mathrm{Si} / \mathrm{Al}$ ratio of $35-5000$ for $\mathrm{ZSM}-5$ at $400{ }^{\circ} \mathrm{C}$ [11]. A correlation between the catalytic performance and the amount of weak and medium acidity was observed $5 \mathrm{wt} \% \mathrm{Mo} / \mathrm{HZSM}-5$ catalyst in the ethanol dehydration [12]. Nevertheless, till now, the complete mechanism for ethanol conversion into ethylene over ZSM-5 was still not fully explained $[13,14]$. Generally, the acid sites and pore structure of zeolites shall be considered when designing ZSM-5 catalyst for the ethanol transformation into hydrocarbons. In recent decades, hierarchically structured zeolites were considered as attractive 
catalysts to explore their improved reactivity, compared with microporous zeolites and mesoporous silicas [15]. For example, a structured ZSM-5 zeolite coated onto $\beta$-SiC foam showed substantial activity/selectivity improvements in alcohols dehydration, when compared to conventional catalyst in the form of powder or extrudates [16].

Among a variety of approaches studied, post-treatments, typically desilication and dealumination, were more convenient and efficient to prepare zeolites with hierarchical structure, which can enhance the diffusion and suppress the coke formation during the catalytic reactions. Till now, the experiments on the posttreated ZSM-5 in the catalytic application of ethanol dehydration reaction are especially rare $[17,18]$. However, these work employed desilication solely [17] or dealumination solely [18] to prepare the post-treated ZSM-5 catalysts for ethanol dehydration. The dehydration reactions were often carried out at higher temperatures (such as $225-425^{\circ} \mathrm{C}$ ) [17], with the products being ethylene, diethyl ether, propene, butenes, paraffins, olefins and aromatics, which made the mechanism study of the reaction system more difficult both experimentally and theoretically.

In this work, we employed herein post-treatments, including desilication with sodium hydroxide, dealumination with oxalic acid, and both of them in a sequential way, to prepare hierarchically porous ZSM-5 catalysts from a commercially available ZSM5 . The catalytic properties of the catalysts were then measured for the ethanol dehydration at $200{ }^{\circ} \mathrm{C}$ and atmospheric pressure. Both the features of acid centers and porous structure were thoroughly addressed experimentally.

As a powerful complementary tool of the experimental approach, theoretical calculation can offer an atomic-level description of a complete reaction mechanism, including not only the structures and energies of the adsorption state, but also the crucial transition state (TS) $[19,20]$. Furthermore, the reaction rate constants that can be derived through the transition-state theory calculation provide direct information to compare with the experimental results and to reveal the origin of the reaction activity and selectivity from the theoretical aspect. For these reasons, it has been extensively used to investigate the influence of acid strength on the acid-catalyzed reaction mechanism [21-29], such as olefinic hydrocarbon protonation [22], ethylene dimerization [23] and alkane activation reactions [25] catalyzed by varying Brønsted acid strengths of solid catalysts.

The reaction mechanisms of ethanol to ethylene and diethyl ether on 8T ZSM-5 acid models were theoretically investigated, aiming at a comprehensive understanding of the influence of acid strength on ethanol conversion over ZSM-5. This contribution may provide an ideal vantage point for distinguishing between the two competitive reactions for the ethylene and diethyl ether formations that coexist in such complex reaction system.

\section{Experimental}

\subsection{Materials}

A commercially available ZSM-5 zeolite was purchased from the Catalyst Plant of Nankai University. Sodium hydroxide $(\mathrm{NaOH})$, ammonium nitrate $\left(\mathrm{NH}_{4} \mathrm{NO}_{3}\right)$, and oxalic acid were purchased from Sinopharm Chemical Reagents Co., Ltd. and used without further purification.

\subsection{Preparation of catalysts}

The post-treatments of the parent ZSM-5 zeolite included desilication and/or dealumination. The desilication treatment of the zeolites was performed in an aqueous $0.2 \mathrm{M} \mathrm{NaOH}$ solution according to a well-established procedure [30]. To this end, $3.3 \mathrm{~g}$ of the sample was vigorously stirred in $100 \mathrm{~mL}$ of $\mathrm{NaOH}$ solution in a polypropylene flask for $30 \mathrm{~min}$ at $65^{\circ} \mathrm{C}$. Subsequently, the reaction was quenched by submersion of the flask in an ice-water mixture, followed by filtration and thorough washing with deionized water. The solid product was dried overnight at $100{ }^{\circ} \mathrm{C}$ and converted into the $\mathrm{H}$-form by three consecutive exchanges in $1 \mathrm{M}$ $\mathrm{NH}_{4} \mathrm{NO}_{3}$ solution $(1 \mathrm{~g}$ of zeolites was vigorously stirred in $30 \mathrm{~mL}$ of $\mathrm{NH}_{4} \mathrm{NO}_{3}$ solution) and subsequent calcination in static air at $550{ }^{\circ} \mathrm{C}$ for $5 \mathrm{~h}$ (ramp rate $1{ }^{\circ} \mathrm{C} \mathrm{min}{ }^{-1}$ ). The suffix -deSi refers to the sample being desilicated by $\mathrm{NaOH}$. The sample after desilication of ZSM-5 was referred as ZSM-deSi.

The dealumination treatment of the zeolites was carried out in an aqueous $0.5 \mathrm{M}$ oxalic acid solution based on a reported procedure [31]. To this end, $1.0 \mathrm{~g}$ of the sample was reacted in $50 \mathrm{~mL}$ of oxalic acid solution in a flask. The mixture was transferred to Teflon container, heated to $120^{\circ} \mathrm{C}$, and kept at this temperature for $2 \mathrm{~h}$. The resulting solid was separated by filtration and washed extensively with deionized water. The solid product was dried overnight at $100{ }^{\circ} \mathrm{C}$ and subsequently calcined in static air at $550{ }^{\circ} \mathrm{C}$ for $5 \mathrm{~h}$ (ramp rate $1{ }^{\circ} \mathrm{C} \mathrm{min}^{-1}$ ). The suffix -deAl refers to the sample being dealuminated by oxalic acid. The sample dealuminated from ZSM-5 was referred as ZSM-deAl. Correspondingly, for the samples upon sequential desilication and dealumination, the one desilicated from ZSM-deAl was referred as ZSM-deAl$\mathrm{deSi}$, and the one dealuminated from ZSM-deSi was referred as ZSM-deSi-deAl.

\subsection{Catalyst characterization}

X-ray diffraction (XRD) pattern was collected on a Bruker D8 Advance diffractometer using $\mathrm{Cu} \mathrm{K} \alpha$ radiation (wavelength $\lambda=1.5147 \AA$ ). The XRD crystallinity was defined as the ratio of the sum of the intensities of the four most intense reflections in the $2 \theta$ range of $22.5-24^{\circ}$ and the corresponding sum for parent ZSM-5 [32]. The Si and Al contents of the calcined zeolites were determined by X-ray fluorescence spectrometer (XRF, Axios PW4400, Panalytical) and Inductively Coupled Plasma Optical Emission Spectrometry (ICP-OES, IRIS Intrepid II XSP, Thermo Fisher), respectively. Nitrogen adsorption-desorption isotherm was measured at $-196{ }^{\circ} \mathrm{C}$ on a Micromeritics ASAP $2020 \mathrm{~m}+\mathrm{c}$ sorptometer. Before measurement, the sample was degassed in a vacuum at $200{ }^{\circ} \mathrm{C}$ for $200 \mathrm{~min}$ (ramp rate $10^{\circ} \mathrm{C} \mathrm{min}^{-1}$ ). The Brunauer-Emmett-Teller method was utilized to calculate the specific surface areas using adsorption data in a relative pressure range from 0.02 to 0.25 . Scanning electron microscopy (SEM) analysis was conducted on a Hitach S-4800 electronic microscope working at $200 \mathrm{kV}$. Transmission electron microscopy (TEM) images were taken using a field emission $\mathrm{H}-7600$ electron microscope at $120 \mathrm{kV}$. All NMR experiments were performed on a Bruker Ascend-500 spectrometer at resonance frequencies of 99.31 and 130.24 MHz for ${ }^{29} \mathrm{Si}$ and ${ }^{27} \mathrm{Al}$, respectively. ${ }^{29} \mathrm{Si}$ NMR experiments were recorded using a $7 \mathrm{~mm}$ triple-resonance MAS probe at a spinning rate of $4 \mathrm{kHz}$. A contact time of $4 \mathrm{~ms}$ and a recycle delay of $2 \mathrm{~s}$ were used for the ${ }^{1} \mathrm{H}^{29} \mathrm{Si}$ CP MAS measurement. ${ }^{29} \mathrm{Si}$ MAS NMR spectra with high power proton decoupling were recorded using a $\pi / 2$ pulse length of $3.9 \mu$ s and a recycle delay of $10 \mathrm{~s} .{ }^{27} \mathrm{Al} \mathrm{NMR}$ experiments were recorded using a $4 \mathrm{~mm}$ triple-resonance MAS probe at a spinning rate of $10 \mathrm{kHz}$. Pulse width $(\pi / 2)$ for ${ }^{27} \mathrm{Al}$ was measured to be $1.7 \mu \mathrm{s} .{ }^{27} \mathrm{Al}$ MAS NMR spectra were recorded using a small-flip-angle technique with a pulse length of $0.28 \mu \mathrm{s}(\pi / 12)$ and a recycle delay of $1 \mathrm{~s}$. The chemical shift of ${ }^{29} \mathrm{Si}$ was externally referenced to kaolinite $(-91.5 \mathrm{ppm})$, while that of ${ }^{27} \mathrm{Al}$ was referenced to $1 \mathrm{M}$ aqueous $\mathrm{Al}\left(\mathrm{NO}_{3}\right)_{3}$. The ammonia temperatureprogrammed desorption ( $\mathrm{NH}_{3}$-TPD) was tested on a Micromeritics Autochem 2920 instrument. The catalyst $(0.15 \mathrm{~g})$ was charged in a 
U-shaped quartz cell and pretreated in $\operatorname{Ar}\left(20 \mathrm{~mL} \mathrm{~min}^{-1}\right)$ at $500{ }^{\circ} \mathrm{C}$ for $1 \mathrm{~h}$ (ramp rate $10^{\circ} \mathrm{C} \mathrm{min}-1$ ), then cooled to $100{ }^{\circ} \mathrm{C}$ followed by changing the gas flow to a mixture of $10 \% \mathrm{NH}_{3}-90 \% \mathrm{Ar}$ $\left(40 \mathrm{~mL} \mathrm{~min}^{-1}\right)$ for $2 \mathrm{~h}$. The sample was then purged with $\mathrm{Ar}$ $\left(20 \mathrm{~mL} \mathrm{~min}^{-1}\right)$ at $100{ }^{\circ} \mathrm{C}$ for $2 \mathrm{~h}$ to remove free and weakly adsorbed ammonia. The $\mathrm{NH}_{3}$-TPD profile was measured by rising the temperature up to $600{ }^{\circ} \mathrm{C}$ (ramp rate $10^{\circ} \mathrm{C} \mathrm{min}-1$ ), using a TCD detector. The quantification of the peak area of $\mathrm{NH}_{3}$-TPD was carried out with a blank U-shaped quartz cell, based on the "Gas Calibration" function of the software attached to Micromeritics Autochem 2920 instrument. In this way, the TCD signal was calibrated to the corresponding concentration of $\mathrm{NH}_{3}$ when the goodness of fit and coefficients were in the accepted range.

\subsection{Catalytic tests}

The catalytic test was performed in a continuous down-flow fixed-bed reactor at $200{ }^{\circ} \mathrm{C}$ under ambient pressure. The catalyst (0.2 g, 60-80 mesh) was mixed with quartz grains $(0.2 \mathrm{~g}, 60-80$ mesh) and placed on quartz wool in the middle of a quartz reactor. Previous in situ activation was performed under helium $\left(23.5 \mathrm{~mL} \mathrm{~min}{ }^{-1}\right.$ ) for $2 \mathrm{~h}$ at $250^{\circ} \mathrm{C}$. The gas flow was kept during reaction, while absolute ethanol was fed into the reactor at $0.01 \mathrm{~mL} \mathrm{~min}^{-1}$, corresponding to an ethanol partial pressure of $19.8 \mathrm{kPa}$ in $\mathrm{He}$ and a space time of 0.422 ( $\mathrm{g}$ of catalyst) $\mathrm{h}$ ( $\mathrm{g}$ of ethanol) ${ }^{-1}$.

Reaction products were continuously monitored by online gas chromatography using an Agilent 7890A gas chromatograph equipped with a FID detector connected to a HP-PLOT Q capillary column ( $30 \mathrm{~m}$ of length, $0.320 \mathrm{~mm}$ of inner diameter and $20.0 \mu \mathrm{m}$ of film thickness).

\subsection{Computational methods}

An $8 \mathrm{~T}$ H-ZSM-5 cluster model of stoichiometry $\left[\left(\mathrm{H}_{3} \mathrm{SiO}\right)_{3}-\right.$ $\left.\mathrm{Si}-\mathrm{OH}-\mathrm{Al} / \mathrm{B}-\left(\mathrm{OSiH}_{3}\right)_{3}\right]$ that extracted from the crystallographic structure of H-ZSM-5 zeolite was used in this work [33], with the

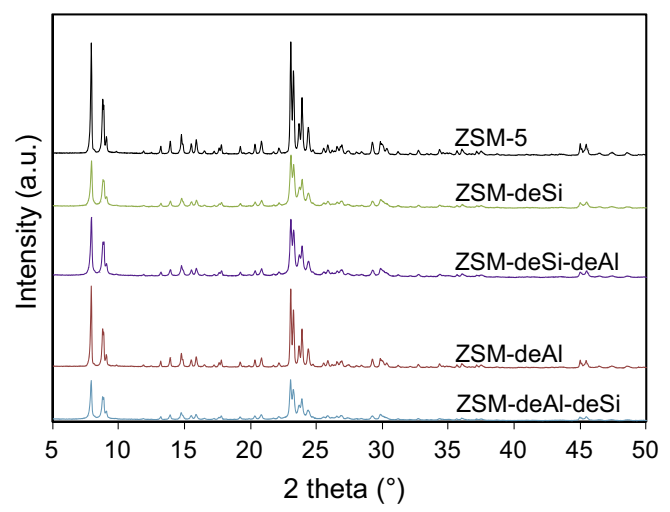

Fig. 1. XRD patterns of parent and post-treated ZSM-5 catalysts.
Si12-O24(H)-Al12 site being used to represent the Brønsted acid site. All the terminal $\mathrm{Si}$ atoms were saturated with $\mathrm{H}$ atoms at a $\mathrm{Si}-\mathrm{H}$ bond length of $1.47 \AA$, orienting along the direction of the corresponding $\mathrm{Si}-\mathrm{O}$ bond. The $\omega \mathrm{B} 97 \mathrm{XD}$ hybrid density function, combined with the moderate $6-31 \mathrm{G}(\mathrm{d}, \mathrm{p})$ basis sets, was employed for all geometry optimizations. This method was a recently developed long-range-corrected hybrid functional by Chai and HeadGordon [34], which implicitly accounted for empirical dispersion and could describe long-range dispersion interactions well with respect to the traditional density functional theory methods. This functional was also recently found to perform very well for the description of adsorption and reactions on zeolites [35,36]. To preserve the integrity of the cluster model structure during the geometry optimizations, the boundary - $\mathrm{SiH} 3$ groups of the cluster model were fixed, while other atoms of the acid site model and the organic adsorbate were allowed to relax. In the calculation, the activation barrier $\left(E_{\text {act }}\right)$ was defined as the single-point energy difference between the transition state of the guest-host system and the absorption complex.

\section{Results and discussion}

\subsection{Experimental part}

\subsubsection{Characterization of the catalysts}

The powder XRD patterns (Fig. 1) of all the five samples exhibited well-resolved diffraction peaks, which were characteristic of the MFI framework structure. Typically, the XRD crystallinities of the post-treated ZSM-5 zeolites were much lower than parent ZSM-5 (Table 1). Notably, the XRD crystallinity of ZSM-deSi showed a dramatic decrease from that of ZSM-5, and ZSM-deAldeSi had a similar trend from ZSM-deAl. That meant that desilication had a considerable influence on the long-range ordering of the zeolite. A similar result was also observed by another research group [37]. In contrast, for acid treatment, the ZSM-5 crystallinity was decreased to $70 \%$ (ZSM-deAl), and ZSM-deSi was quite close to ZSM-deSi-deAl. Compared with desilication, the effect of dealumination on the long range integrity of the zeolite was relatively small. We also calculated the lattice spacings of all the five catalysts from fitted XRD data and compared with the lattice spacings of a standard ZSM-5 in the database. For the orthorhombic structure of ZSM-5, the lattice constants ( $a$-axis, $b$-axis and $c$-axis) were given in Table S1 (see Supplementary information SI-1). All the samples showed very similar $a$-axis, $b$-axis and $c$-axis values to those of ZSM-5-standard from the database, expect for ZSM-deSideAl, which showed relatively smaller $b$-axis value and larger $c$-axis value. The reason for the unexpected data of ZSM-deSi-deAl was not clear yet, but seemingly the post-treatments could not substantially change the lattice parameters.

Fig. 2 displayed nitrogen sorption isotherms of the various ZSM5 catalysts. The isotherm of ZSM- 5 was of type I, which is typical for microporous zeolite. The sharp uptake at relative pressure $P /$ $P_{0}<0.05$ confirmed the presence of micropores. The isotherm of

Table 1

Textural properties of parent and post-treated ZSM-5 zeolites.

\begin{tabular}{|c|c|c|c|c|c|}
\hline Catalyst & XRD crystallinity (\%) & BET surface area $^{a}\left(\mathrm{~m}^{2} \mathrm{~g}^{-1}\right)$ & External surface area ${ }^{\mathrm{b}}\left(\mathrm{m}^{2} \mathrm{~g}^{-1}\right)$ & Mesopore volume ${ }^{\mathrm{c}}\left(\mathrm{cm}^{3} \mathrm{~g}^{-1}\right)$ & Micropore volume $^{\mathrm{b}}\left(\mathrm{cm}^{3} \mathrm{~g}^{-1}\right)$ \\
\hline ZSM-5 & 100 & 393 & 27 & 0.04 & 0.16 \\
\hline ZSM-deSi & 55 & 425 & 88 & 0.23 & 0.15 \\
\hline ZSM-deSi-deAl & 58 & 383 & 79 & 0.22 & 0.13 \\
\hline ZSM-deAl & 70 & 400 & 25 & 0.04 & 0.16 \\
\hline ZSM-deAl-deSi & 40 & 331 & 74 & 0.16 & 0.11 \\
\hline
\end{tabular}

a BET method.

b t-Plot method.

c BJH method (adsorption branch). 


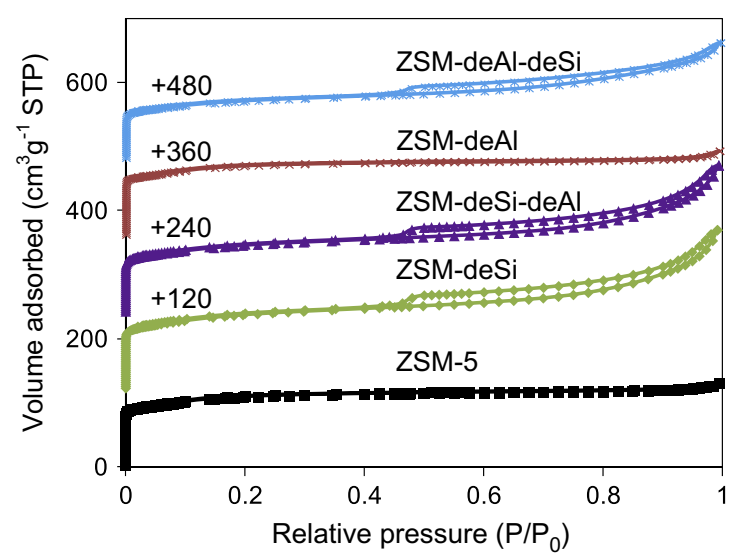

Fig. 2. Nitrogen sorption isotherms for parent and post-treated ZSM-5 catalysts.

ZSM-deAl was very close to that of ZSM-5, with almost same BET surface area, mesopore volume and micropore volume (Table 1). Moreover, the isotherm of ZSM-deSi-deAl was also similar to that of ZSM-deSi, but with slightly decreased BET surface area. The three samples involving desilication displayed a hysteresis loop in the sorption isotherms, implying the presence of mesopores, whereas the samples ZSM-5 and ZSM-5-deAl contained almost no mesopore volume $\left(0.04 \mathrm{~cm}^{3} \mathrm{~g}^{-1}\right)$ or small external surface area (ca. $25 \mathrm{~m}^{2} \mathrm{~g}^{-1}$ ), which was evidenced by the BJH mesopore size distributions in Fig. 3. These results indicated that the dealumination treatment had smaller effect on the pore structure than desilication.

SEM images of the samples were shown in Fig. 4. The parent ZSM-5 had a smooth surface with typical coffin shape and uniform crystallite size of $1.5-2.5 \mu \mathrm{m}$. The acid-treated sample ZSM-deAl showed no obvious structural destruction, as confirmed by the nitrogen sorption results (Figs. 2 and 3). For the other three samples involving desilication treatment, their morphology was generally similar with relatively rough surface and irregular shape. The surface roughness of base-treated samples was much more visible than that of the acid-treated sample. This was in compliance with SEM images reported in an early study [31]. The SEM images with higher magnifications were shown in Fig. S1 (see Supplementary information SI-2). As can be seen in the figure, ZSM-5 and ZSM-deAl showed a quite smooth surface of the ZSM-5 crystals, indicating that the dealumination did not destroy the overall morphology and structure significantly. For ZSM-deSi, ZSM-deSi-deAl, and ZSM-deAl-deSi, the samples involving the desilication treatment demonstrated a seriously etched surface by alkaline.

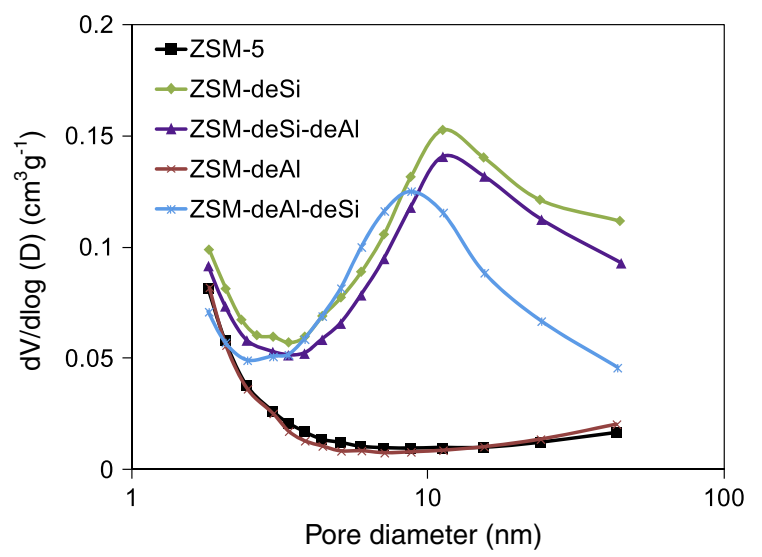

Fig. 3. BJH mesopore size distributions of parent and post-treated ZSM-5 catalysts.
TEM images were shown in Fig. S2 (see Supplementary information SI-2). ZSM-deAl showed hardly any contrast differences within the crystals, as compared with parent ZSM-5, indicating that the dealumination by oxalic acid did not destruct the crystal structure substantially. For the alkaline-treated samples (ZSMdeSi, ZSM-deSi-deAl, and ZSM-deAl-deSi), significant mesoporosity was created, as identified by the whiter tonality in the zeolite crystals. The TEM results were consistent with SEM and HR-SEM images.

Since the desilication and dealumination employed in this work may directly influence the $\mathrm{Si}$ and $\mathrm{Al}$ coordination in zeolite framework, respectively, the ${ }^{29} \mathrm{Si}$ and ${ }^{27} \mathrm{Al}$ MAS NMR were done to further uncover the structural changes upon the post-treatments. The ${ }^{29} \mathrm{Si} \mathrm{HPDEC} \mathrm{MAS} \mathrm{NMR} \mathrm{spectra} \mathrm{(Fig.} \mathrm{5)} \mathrm{were} \mathrm{supposed} \mathrm{to} \mathrm{pres-}$ ent quantitative analysis of different tetrahedral sites of silicon atoms. The deconvolution of ${ }^{29} \mathrm{Si}$ spectrum may result in four peaks centered at -98 to $-100 \mathrm{ppm}(\mathrm{SiOH}),-106 \mathrm{ppm}(\mathrm{Si}(3 \mathrm{Si}, 1 \mathrm{Al}))$, and -113 and $-116 \mathrm{ppm}(\mathrm{Si}(4 \mathrm{Si}))$. The $\mathrm{Si} / \mathrm{Al}$ ratios $[38,39]$ from ${ }^{29} \mathrm{Si}$ HPDEC MAS NMR spectra were summarized in Table 2, which showed similar trend to the $\mathrm{Si} / \mathrm{Al}$ ratios determined by XRF and ICP-OES. The desilication resulted in a sharp decrease in $\mathrm{Si}(4 \mathrm{Si})$ proportion and a corresponding increase in $\mathrm{Si}(3 \mathrm{Si}, 1 \mathrm{Al})$ proportion, with an increase in $\mathrm{SiOH}$ amount for ZSM-deSi, as compared with original ZSM-5. It is generally accepted that, during desilication, the $\mathrm{Si}$ species such as $\mathrm{Si}(4 \mathrm{Si})$ can easily be leached out but it is difficult to remove the $\mathrm{Si}$ species such as $\mathrm{Si}(3 \mathrm{Si}, 1 \mathrm{Al})$ because the negatively charged $\mathrm{AlO}_{4}$ tetrahedra can prevent the hydrolysis of the $\mathrm{Si}-\mathrm{O}-\mathrm{Al}$ bond in alkaline solution [40]. The desilicated sample was then dealuminated, resulting in almost no change of $\mathrm{Si}(4 \mathrm{Si})$ proportion and a dramatic increase in $\mathrm{SiOH}$ proportion. The content of $\mathrm{Si}(3 \mathrm{Si}, 1 \mathrm{Al})$, which was probably associated with Brønsted acid site, decreased from $17.21 \%$ to $12.72 \%$, indicating that acid leaching obviously removed the $\mathrm{Al}$ species in the framework. As the sample dealuminated directly from ZSM-5, ZSM-deAl contained almost same amount of $\mathrm{Si}(3 \mathrm{Si}, 1 \mathrm{Al})$ and $\mathrm{Si}(4 \mathrm{Si})$. However, further desilication of ZSM-deAl resulted in ZSM-deAl-deSi containing more Si(3Si, $1 \mathrm{Al}$ ) and $\mathrm{SiOH}$ with a sharp decrease in $\mathrm{Si} / \mathrm{Al}$ ratio.

From the relative intensities of ${ }^{29} \mathrm{Si}$ NMR peaks, some information about the desilication and dealumination can be deduced. We tentatively studied whether it was a completely random process, or there was a preferential removal of $\mathrm{Si}$ (or $\mathrm{Al}$ ) atoms at some special T sites. By comparing Fig. 5(a) and (b), only slight change for the $\mathrm{Q}(4 \mathrm{Si})$ with the relative lower-field ${ }^{29} \mathrm{Si}$ chemical shift (from $68.21 \%$ to $65.18 \%$ ) was observed. However, considerable change was observed for the $\mathrm{Q}(4 \mathrm{Si})$ with the relative high-field ${ }^{29} \mathrm{Si}$ chemical shift (from $23.34 \%$ to $16.60 \%$ ). Therefore, it was indicative that the desilication was selectively occurring at the $\mathrm{Q}(4 \mathrm{Si})$ with highfield ${ }^{29} \mathrm{Si}$ chemical shift. The similar trend was found for ZSM-deAl and ZSM-deAl-deSi (see Fig. 5(d) and (e)) that the intensity changes for $\mathrm{Si}(4 \mathrm{Si})$ at -113 and $-116 \mathrm{ppm}$ were $4 \%$ and $9 \%$, respectively. It is well known that the ${ }^{29} \mathrm{Si}$ MAS NMR signals of the silicon species at different crystallographically non-equivalent $\mathrm{T}$ sites are strongly correlated with different bond geometries of the corresponding $\mathrm{SiO}_{4}$ tetrahedral in the zeolite framework. Generally, the $\mathrm{Si}$ atom with a large $\mathrm{T}-\mathrm{O}-\mathrm{T}$ angle was attributed to most high-field ${ }^{29} \mathrm{Si}$ chemical shift. ${ }^{29} \mathrm{Si}$ NMR shieldings increase and the shifts thus become more negative with increasing $\mathrm{T}-\mathrm{O}-\mathrm{T}$ bond angle as demonstrated both experimentally and through quantum computations [41-43]. On the basis of the ZSM-5 crystallographic structure, 12 different $\mathrm{T}$ sites were involved, and the average bond angles of $\mathrm{T} 3, \mathrm{~T} 4, \mathrm{~T} 8$, and $\mathrm{T} 11$ were within a range of average $\mathrm{T}-\mathrm{O}-\mathrm{T}$ angles between 158.7 and 160.6 degree, and the other eight $\mathrm{T}$ sites, with a range of average $\mathrm{T}-\mathrm{O}-\mathrm{T}$ angles between 150.4 and 156.4 degree [44]. Therefore, the T3, T4, T8 and T11 in ZSM-5 were possibly preferential $\mathrm{T}$ sites in desilication. Note that for the dealumination reaction, the intensity changes of two $\mathrm{Si}(4 \mathrm{Si})$ peaks were ca. $1-2 \%$ 

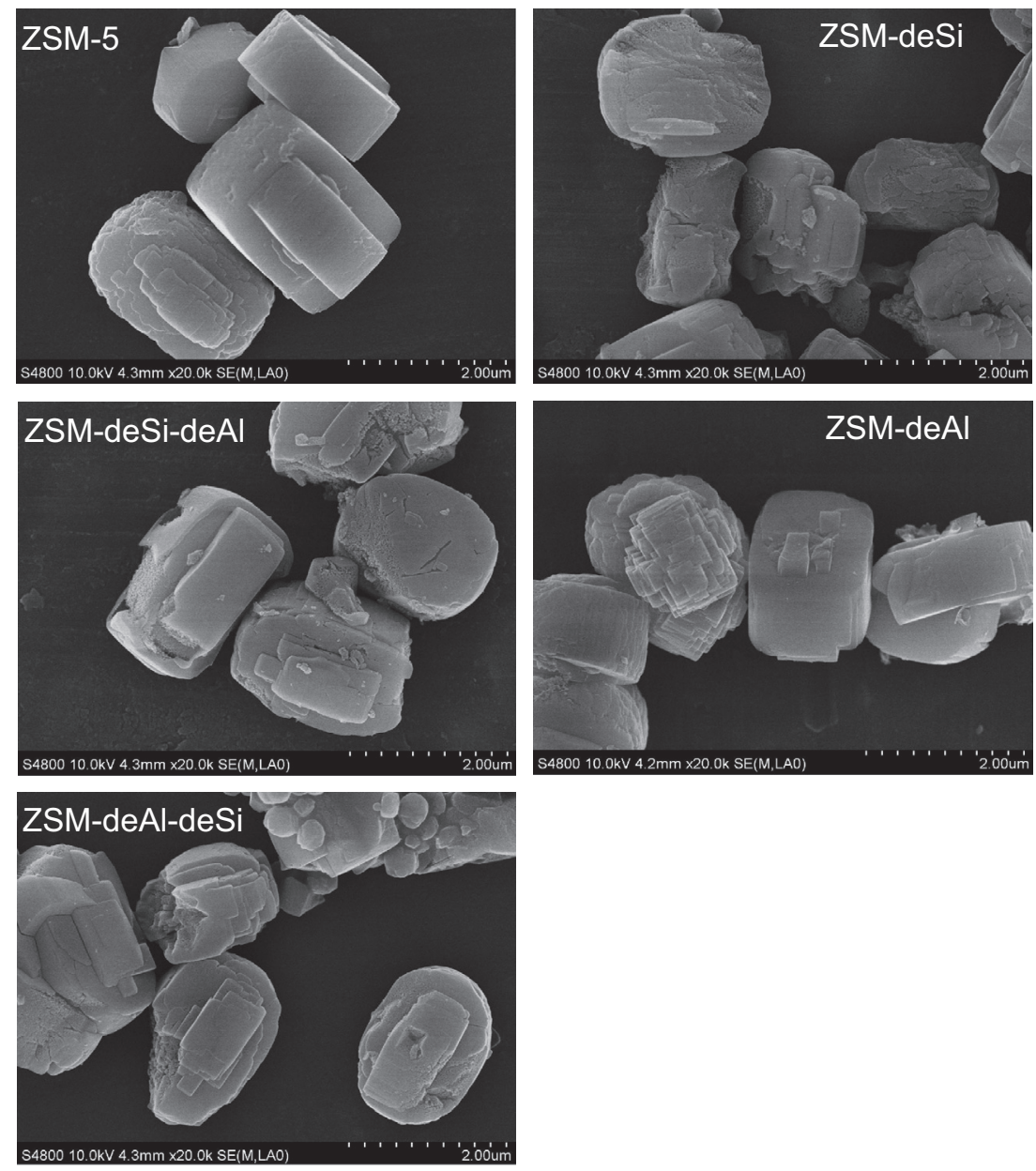

Fig. 4. Scanning electron micrographs of parent and post-treated ZSM-5 catalysts.
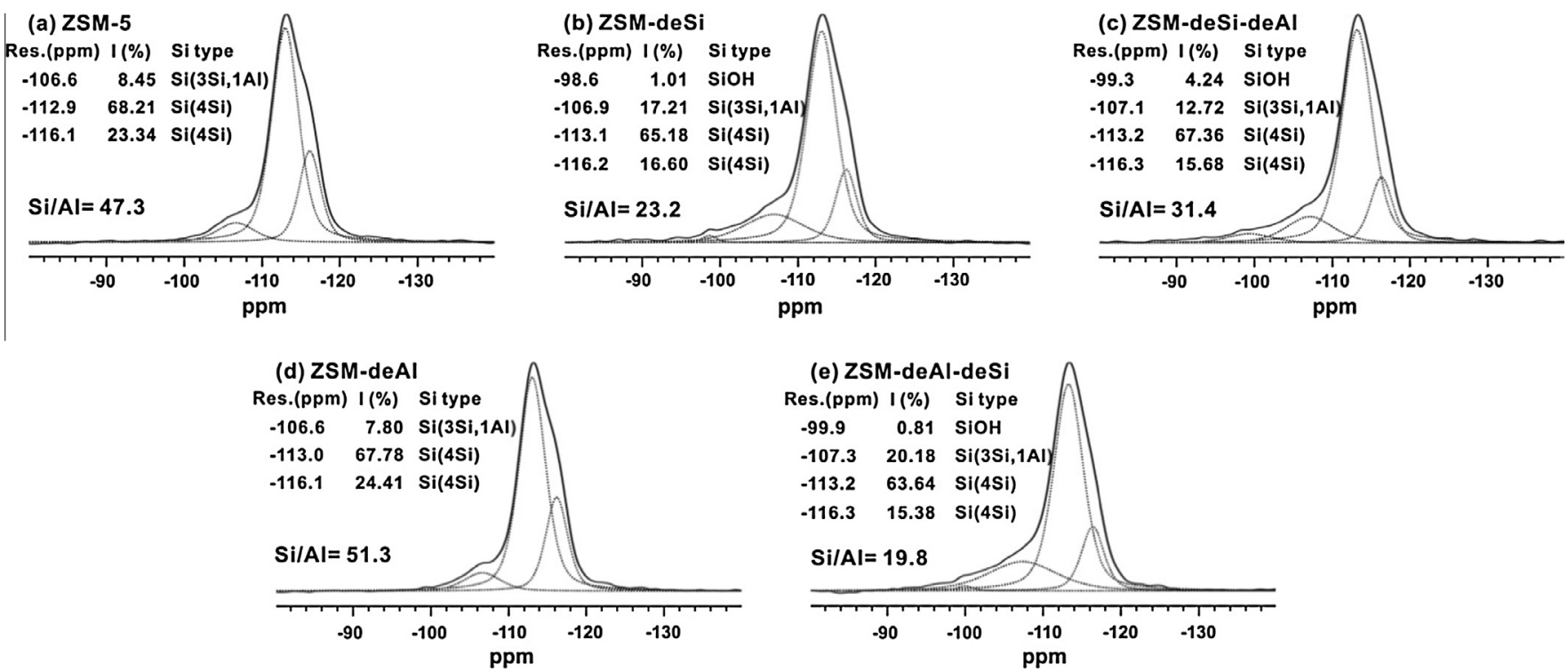

Fig. 5. ${ }^{29}$ Si HPDEC MAS NMR spectra of parent and post-treated ZSM-5 catalysts: (a) ZSM-5, (b) ZSM-deSi, (c) ZSM-deSi-deAl, (d) ZSM-deAl, and (e) ZSM-deAl-deSi.

and did not show much difference in ZSM-5 and ZSM-deAl (see Fig. 5(a) and (d)), and in ZSM-deSi and ZSM-deSi-deAl (see Fig. 5(b) and (c)). Apparently, the dealumination in ZSM-5 was a completely random process. The investigation of the detailed rea- son (kinetically or dynamically controlled process) for the random dealumination in ZSM-5 is in progress.

Fig. 6 presented ${ }^{1} \mathrm{H}^{29}{ }^{29} \mathrm{Si}$ cross-polarization (CP) MAS NMR spectra of the samples. ${ }^{1} \mathrm{H}^{2}{ }^{29} \mathrm{Si}$ CP MAS NMR experiment can be used to 
Table 2

Chemical composition of parent and post-treated ZSM-5 zeolites.

\begin{tabular}{|c|c|c|c|c|c|}
\hline Catalyst & $\mathrm{Si} / \mathrm{Al}^{\mathrm{a}}$ & $\mathrm{Si} / \mathrm{Al}^{\mathrm{b}}$ & Weak acid/strong acid ${ }^{\mathrm{C}}$ & $\mathrm{NH}_{3}$ chemisorbed $^{\mathrm{c}}\left(\mathrm{mmol} \mathrm{g}^{-1}\right)$ & Turnover frequency $\left(\mathrm{s}^{-1}\right)$ \\
\hline ZSM-5 & 58 & 47 & 1.23 & 1.55 & 0.0067 \\
\hline ZSM-deSi & 28 & 23 & 1.43 & 1.80 & 0.0059 \\
\hline ZSM-deSi-deAl & 38 & 31 & 1.29 & 1.20 & 0.0084 \\
\hline ZSM-deAl & 41 & 51 & 1.26 & 1.37 & 0.0076 \\
\hline ZSM-deAl-deSi & 29 & 20 & 1.43 & 1.50 & 0.0070 \\
\hline
\end{tabular}

XRF and ICP-OES

b ${ }^{29} \mathrm{Si}$ HPDEC MAS NMR.

c $\mathrm{NH}_{3}$-TPD.

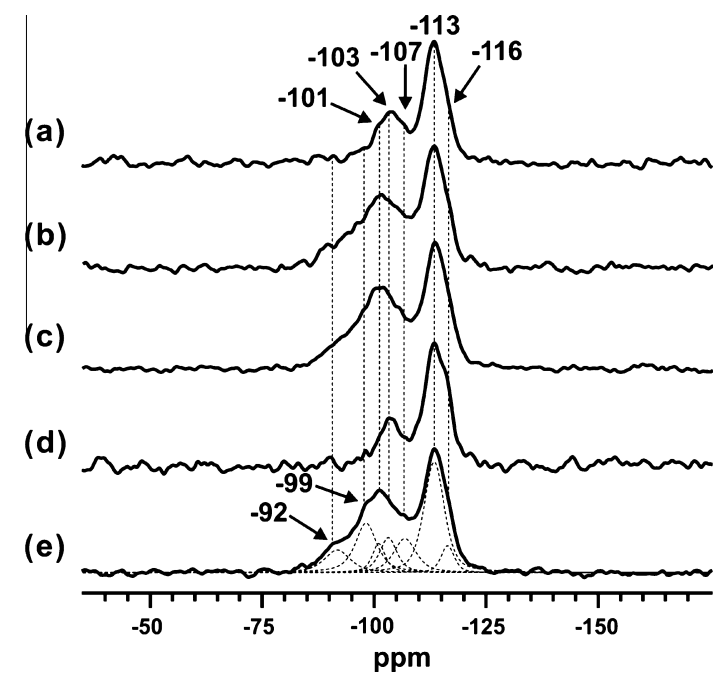

Fig. 6. ${ }^{1} \mathrm{H}-{ }^{29} \mathrm{Si} C P$ MAS NMR spectra of parent and post-treated ZSM-5 catalysts: (a) ZSM-5, (b) ZSM-deSi, (c) ZSM-deSi-deAl, (d) ZSM-deAl, and (e) ZSM-deAl-deSi.

enhance the signal of ${ }^{29} \mathrm{Si}$ nuclei by magnetization transfer from ${ }^{1} \mathrm{H}$ nuclei, thus estimating the spatial proximity of the Si and hydroxyl $(\mathrm{OH})$ groups. Compared with ZSM-5, ZSM-deSi showed more intense signals between -99 and $-101 \mathrm{ppm}$, illustrating the desilication may generate large amount of $\mathrm{Si}-\mathrm{OH}$ groups. ZSMdeSi-deAl (Fig. 6(c)) contained more intense signals between -99 and $-101 \mathrm{ppm}$, which also implied that the desilication followed by dealumination may further produce more $\mathrm{Si}-\mathrm{OH}$, in agreement with ${ }^{29}$ Si HPDEC MAS NMR spectra (Fig. 5). In contrast, the dealumination of original ZSM-5 did not significantly lead to an increase in the $\mathrm{Si}-\mathrm{OH}$ signals. The following desilication also generated more intense $\mathrm{Si}-\mathrm{OH}$ signals at $-92,-99$ and $-101 \mathrm{ppm}$. Note that, the $\mathrm{Si}-\mathrm{OH}$ signals of parent ZSM-5 were also found in ${ }^{1} \mathrm{H}-{ }^{29} \mathrm{Si} \mathrm{CP}$ MAS NMR spectrum (Fig. 6(a)), but not in ${ }^{29}$ Si HPDEC MAS NMR spectrum (Fig. 5(a)), which indicated that the concentration of $\mathrm{Si}-\mathrm{OH}$ on crystal surface of ZSM-5 was very low.

${ }^{27} \mathrm{Al}$ MAS NMR was used to detect the coordination state of aluminum species in the catalysts (Fig. 7). Apparently, in all cases, the samples exhibited a strong peak centered at around $54 \mathrm{ppm}$, corresponding to tetrahedrally coordinated aluminum (framework $\mathrm{Al}$, $\mathrm{FAl}$ ), and a small peak centered at around $0.6 \mathrm{ppm}$ (extra-framework $\mathrm{Al}, \mathrm{EFAl}$ ), which was related to octahedrally coordinated aluminum. This indicated that $\mathrm{Al}$ in all the samples was mainly tetrahedrally coordinated. Generally, all the treatments did not change the proportions of FAl and EFAl substantially. Compared with ZSM-5, the spectrum width of ZSM-deSi was slightly enlarged, which implied that the desilication resulted in the nonuniform distribution for the framework $\mathrm{Al}$ atoms to some extent. Furthermore, upon desilication treatment, ${ }^{27} \mathrm{Al}$ peak became asymmetric at ca. $45 \mathrm{ppm}$ as shown in Fig. 7, which was possibly attributed to the distorted four-coordinated aluminum or

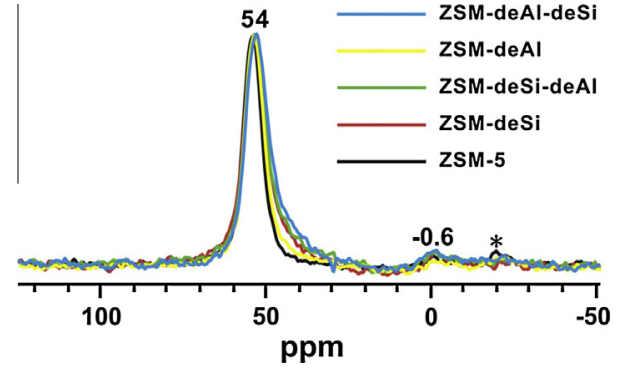

Fig. 7. ${ }^{27} \mathrm{Al}$ MAS NMR spectra of parent and post-treated ZSM-5 catalysts.

five-coordinated aluminum [45]. But the following dealumination did not alter the width prominently, illustrating that the treatment may not affect the Al coordination significantly. Similar trends were found for dealumination from ZSM-5 and desilication from ZSM-deAl. The dealumination of ZSM-5 did not change the Al environment and structural integrity obviously, in accordance with the results of nitrogen sorption (Figs. 3 and 4), which was different from reported results $[46,47]$. The reason might be that the dealumination process employed in this work was too mild to alter the Al coordination substantially.

The $\mathrm{NH}_{3}$-TPD was used to characterize the surface acidity of ZSM-5 zeolites [48]. Although the $\mathrm{NH}_{3}$-TPD technique has some drawbacks $[49,50]$, it is a fast, relatively simple and frequently employed method to evaluate the acidity in catalysts. Previously, the acid density was determined by titration of the ammonia at the outlet of the TCD with $\mathrm{H}_{3} \mathrm{BO}_{3}$ solution and back titration with $\mathrm{H}_{2} \mathrm{SO}_{4}$ solution [51,52]. In this study, we calibrated the TCD signal to the corresponding concentration of $\mathrm{NH}_{3}$ with the "Gas Calibration" function of the software attached to Micromeritics Autochem 2920 instrument. Since $\mathrm{NH}_{3}$-TPD technique suffered from many conflicts, great care was taken in order to eliminate the physical adsorption phenomena (ammonia adsorption at $100{ }^{\circ} \mathrm{C}$ and thorough flushing with helium prior to desorption) and to eliminate the unavoidable mass transfer problems by calculation. We believed that such a procedure can provide semi-quantitative data on the acid density of the zeolites. Generally, for metal oxides [53,54], silica (or silica-alumina) [55-57] and zeolites [58-61], the ammonia desorption peaks at lower temperatures were attributed to weak or medium acid sites, while the peaks at higher temperatures were related to strong acid sites.

As shown in Fig. 8, there were two ammonia desorption peaks for all the catalysts, and these desorption peaks corresponded to two different types of acid sites. The low-temperature desorption peak centered at ca. $200^{\circ} \mathrm{C}$ was attributed to weak acid sites, and the high-temperature desorption peak at ca. $415{ }^{\circ} \mathrm{C}$ was due to ammonia bonded to strong acid sites [62]. After the deconvolution and ammonia quantification [12], each $\mathrm{NH}_{3}$-TPD curve was deconvoluted by the Gauss curve fitting method into two separated peaks, from which the amounts of weak and strong acid sites were calculated, as summarized in Fig. 9. For the five catalysts, the 


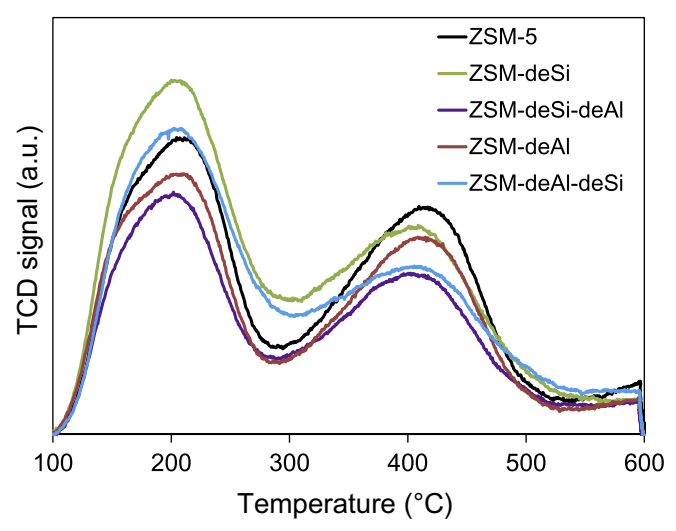

Fig. 8. $\mathrm{NH}_{3}$-TPD profiles of parent and post-treated $\mathrm{ZSM}-5$ catalysts.

amounts of weak acid sites were larger than those of strong acid sites. However, different from previous work on microporous ZSM-5 with different Si/Al ratios [9], no direct relation between $\mathrm{Si} / \mathrm{Al}$ ratio and acid density was found here, probably due to partial contribution of structural integrity to total acid content. Upon desilication, ZSM-deSi owned much more amount of weak acid sites than original ZSM-5, despite there was a slight increase in the strong acid sites. Same trend was also found for ZSM-deAl and ZSM-deAl-deSi. This implied that the desilication treatment could obviously increase the weak acid, which was in accordance with reported results [17,63]. For ZSM-deAl with little change of porous structure (as illustrated in Figs. 2 and 4), both the weak and strong acid sites were decreased as compared with parent ZSM-5, and similar trend was also found for ZSM-deSi and ZSM-deSi-deAl. For the samples with sequential desilication and dealumination treatments, ZSM-deAl-deSi contained much more weak acid sites than ZSM-deSi-deAl. The total number of acid sites $\left(\mathrm{NH}_{3}\right.$ chemisorbed) was listed in Table 2. The total acid number was $1.55 \mathrm{mmol} \mathrm{g}^{-1}$ for ZSM-5, more than the treated samples, except for ZSM-deSi $\left(1.80 \mathrm{mmol} \mathrm{g}^{-1}\right)$. The ratios of weak acid sites to strong acid sites were calculated (see Table 2). Overall, desilication could increase the ratio of weak acid sites to strong ones, which was consistent with reported results $[59,64]$.

To ensure that the $\mathrm{NH}_{3}$-TPD data were not affected by the lag time for gas to diffuse out of zeolite pores, an analysis was carried out using the criterion of Gorte [65] and Ibok and Ollis [66]. It was suggested that the effect of diffusion limitations could be neglected

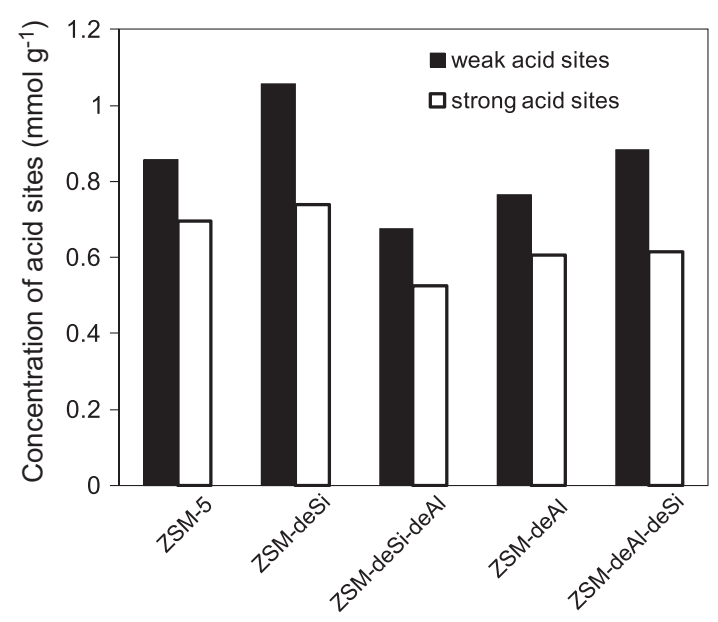

Fig. 9. Concentration of weak acid sites and strong acid sites of parent and posttreated ZSM-5 catalysts as calculated from $\mathrm{NH}_{3}$-TPD profiles. for a value of less than 0.01 for the group $\frac{\beta l^{2} s}{\left(T_{f}-T_{0}\right) D}$, where $\beta$ is the heating rate $(\mathrm{K} / \mathrm{s}), l$ is the width of catalyst $\mathrm{slab}(\mathrm{cm}), \varepsilon$ is the porosity $\left(\mathrm{cm}^{3} / \mathrm{cm}^{3}\right), T_{f}$ and $T_{0}$ are the final and initial temperature (K), respectively, and $D$ is the effective diffusivity $\left(\mathrm{cm}^{2} / \mathrm{s}\right)$. For our experiment, a highest value of $1.9 \times 10^{-6}$ was obtained (see Table S2 in Supplementary information SI-3), and this indicated no diffusion limitations during the $\mathrm{NH}_{3}$-TPD experiments.

In the $\mathrm{NH}_{3}$-TPD experiment, the strong acid sites were generally attributed to the bridge $\mathrm{Al}-\mathrm{OH}-\mathrm{Si}$ in the 10 -member ring (10-MR) of ZSM-5 [67], and the assignment of weak acid sites should be tentatively discussed in details with combined NMR and TPD results. It was observed experimentally that silanol nests were formed for ZSM-5 after desilication with $\mathrm{NaOH}$ solution, which resulted in an increase in SiOH concentrations in ZSM-deSi (Figs. 5 and 6). It was noteworthy that such silanol nests were one of the possible origins of weaker Brønsted acid in the zeolites [9,11,68], despite that silanol groups were recognized as neutral or very weakly acidic [69]. While ZSM-deSi was then treated with the oxalic acid solution, the Al species were released from the zeolite framework and $\mathrm{Si} / \mathrm{Al}$ ratio was increased to 31 from 23 of ZSM-deSi. According to the relative intensity of each Si sites of ZSM-deSi-deAl, Si(4Si) was almost remained compared to ZSMdeSi; however, the intensity of $\mathrm{Si}(3 \mathrm{Si}, 1 \mathrm{Al})$ decreased significantly during dealumination process (Fig. 5). Correspondingly, both the weak and strong acidic sites were substantially reduced as observed in $\mathrm{NH}_{3}$-TPD results (Fig. 8). This might indicate that the weak acid sites were also correlated with $\mathrm{Si}(3 \mathrm{Si}, 1 \mathrm{Al})$. As shown in Fig. 5(c), the weak acidic SiOH was increased about fourfold; however, the amount of weaker acid was significantly decreased in the $\mathrm{NH}_{3}$-TPD results. Similar varying trends in the weak acid sites and strong acid sites were also observed for ZSM-deAl and ZSM-deAl-deSi. Therefore, besides the SiOH group, some weak bridge $\mathrm{Al}-\mathrm{OH}-\mathrm{Si}$ groups were also possibly attributed to the weak acid sites at lower $\mathrm{NH}_{3}$-desorption temperature in $\mathrm{NH}_{3}$-TPD spectra. The strongest Brønsted sites were normally located in the well crystallized areas, whereas the weakest ones were found in the areas of lower crystallinity [70]. Since the desilication and dealumination would lower the crystallinity (Table 1), the weak bridge $\mathrm{Al}-\mathrm{OH}-\mathrm{Si}$ groups might exist in these samples. Therefore, the significant increase in $\mathrm{Si}(3 \mathrm{Si}, 1 \mathrm{Al})$ intensity (Fig. 5) in desilicated samples (ZSM-deSi and ZSM-deAl-deSi) might include the bridge $\mathrm{Al}-\mathrm{OH}-\mathrm{Si}$ groups with weaker acidity probably in the low-crystallinity area. It was also reported that the desilication could convert some of the strong Brønsted acid sites into sites of weaker acidity or modify the accessibility of these sites due to the partial removal of silica [59].

In fact, the exact chemical nature of the acid sites is still a matter of debate [62,71]. However, It is generally accepted that the primary reactions involved in the conversion of alcohol to lower hydrocarbons can occur on weak acid sites, but the subsequent reactions (e.g., oligomerization, dehydrocyclization and hydrogenation) occur on the strong acid sites with comparatively higher acid strength $[4,72-74]$.

\subsubsection{Catalytic performance}

To evaluate the reactivity of the ZSM-5 catalysts, the ethanol dehydration was investigated at $200{ }^{\circ} \mathrm{C}$. The products in the reaction consisted of almost exclusively ethylene and diethyl ether, due to the low reaction temperature. This made the reaction system relatively less complicate to study, since more products including higher hydrocarbons were formed inevitably at higher temperatures in this reaction system [62].

The conversion of ethanol with time-on-stream over various catalysts was shown in Fig. 10. All the catalysts gave a stable catalytic activity, with a comparable ethanol conversion capacity of $70-76 \%$ after a reaction time-on-stream of approximately $2 \mathrm{~h}$. 


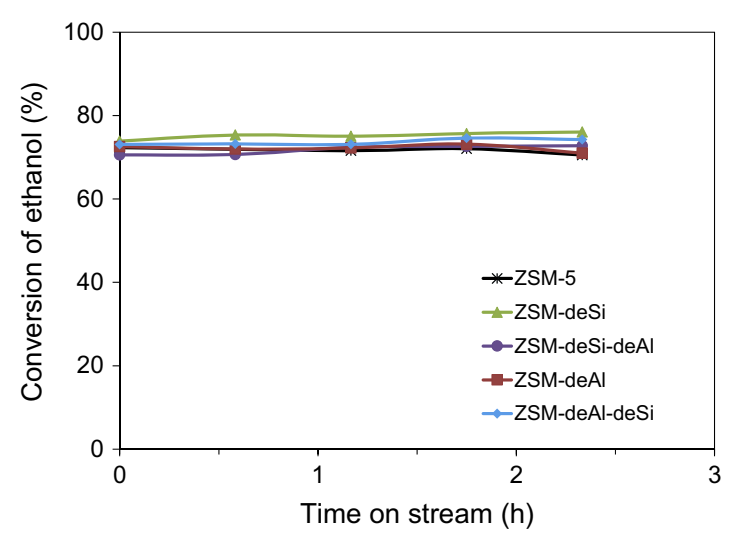

Fig. 10. The conversion of ethanol over parent and post-treated ZSM-5 catalysts. Reaction conditions: $200{ }^{\circ} \mathrm{C}$, ethanol pressure in $\mathrm{He}=19.8 \mathrm{kPa}$, space time $=0.422$ ( $\mathrm{g}$ of catalyst) h ( $\mathrm{g}$ of ethanol) $)^{-1}$.

It was reported that HZSM-5 catalysts treated with $\mathrm{NaOH}$ for different time showed almost the same ethanol conversion at the reaction temperature of $250-275^{\circ} \mathrm{C}$ [17]. However, the selectivity of ethylene varied more pronounced for the five catalysts (Fig. 11). Generally, after desilication, the selectivities of ZSM-deSi and ZSMdeAl-deSi were higher than their parent one, i.e. ZSM-5 and ZSMdeAl, respectively; instead, the dealumination resulted in lowered ethylene selectivities from ZSM-5 and ZSM-deSi to ZSM-deAl and ZSM-deSi-deAl, respectively.

The turnover frequencies were obtained using the following formula [75]:

(Turnover frequency $\left(\mathrm{s}^{-1}\right)$

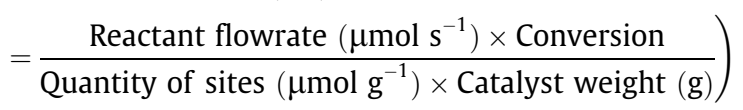

A summary of the turnover frequencies of all the catalysts was provided in Table 2.

In order to reveal the reason why ZSM-deSi exhibited remarkably enhanced ethylene yield in the reaction, the relations between catalytic performance of ethanol dehydration and structural properties of the catalysts were carefully considered.

Firstly, the effect of texture structure on the reactivity was correlated. Generally, the mesoporous/microporous structure of hierarchical zeolites may benefit catalysis reactions, which was mainly contributed to their enhanced diffusion features [76]. In this work, since the ethanol dehydration at low temperature was not a typical

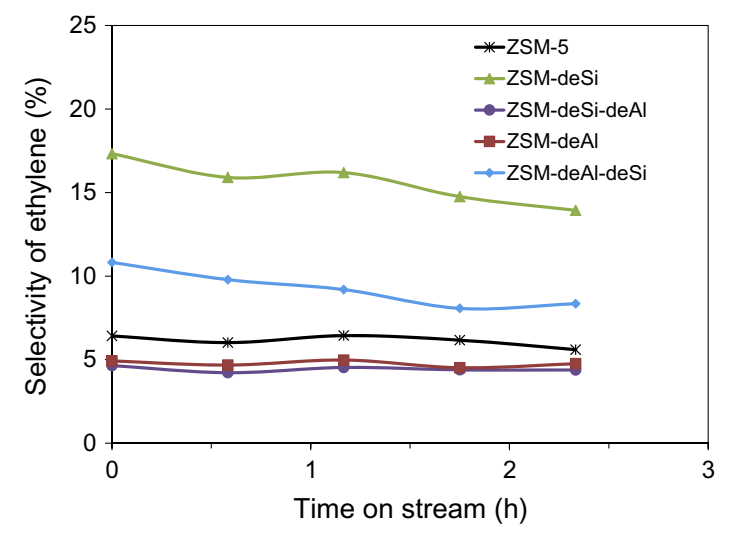

Fig. 11. The selectivity of ethylene over parent and post-treated ZSM-5 catalysts. Reaction conditions: $200{ }^{\circ} \mathrm{C}$, ethanol pressure in $\mathrm{He}=19.8 \mathrm{kPa}$, space time $=0.422$ ( $\mathrm{g}$ of catalyst) h ( $\mathrm{g}$ of ethanol $)^{-1}$. space-demanding or coke-forming reaction, the hierarchical structure may not benefit the ethanol transformation substantially, resulting in very similar ethanol conversion for the catalysts. In addition, no direct relations between BET surface area (or mesopore volume) and ethylene yield (or ethylene selectivity) were observed. For example, both ZSM-deSi-deAl and ZSM-deAl-deSi contained higher mesopore volume, but ZSM-deSi-deAl showed the lowest ethylene selectivity; for ZSM-deSi and ZSM-deSi-deAl with comparable mesopore volume, their ethylene selectivity differed noticeably, despite their BET surface area varied. The effects of crystallinity from XRD on the catalytic property were also not found. Therefore, the hierarchically porous structure could not reasonably explain the discrepancy in catalytic results.

Secondly, the effect of acidity on ethylene selectivity was studied. For microporous ZSM-5, the Si/Al ratio had a relation with total acidity [9]. In previous study, the influence of Si/Al ratio on catalytic performance of ethanol transformation over ZSM-5 zeolites was studied, and higher $\mathrm{Si} / \mathrm{Al}$ ratio could increase the ethylene yield under the condition of $400{ }^{\circ} \mathrm{C}$ and 1 bar [11], $500{ }^{\circ} \mathrm{C}$ and 1 bar [77] or $350{ }^{\circ} \mathrm{C}$ and 30 bar [10]. But in our case, the ethylene yield had no correlation with $\mathrm{Si} / \mathrm{Al}$ ratio and total acidity (calculated as $\mathrm{NH}_{3}$ chemisorbed from $\mathrm{NH}_{3}$-TPD, Table 2), probably due to the randomly distributed acid sites through post-treatments.

With the data in Figs. 9-11, a correlation profile can be obtained (Fig. 12). The relation of the steady-state ethylene selectivity (after time-on-stream of $2.33 \mathrm{~h}$ ) and the total weak acid sites indicated that the steady-state ethylene selectivity increased with the number of weak acid sites. Clearly, the weak acid sites were favorable to the ethanol conversion to ethylene at low temperature. Different from the early reports on zeolite catalysts with quite different topologies or same topology with different Si/Al ratios, in this study the preparation processes of four post-treated catalysts were all originated from the parent ZSM-5. Therefore, their structures were closely related to each other with good comparability. The relationship demonstrated that the weak acid centers most likely benefited the ethylene formation. Under present reaction conditions, there were simply two main products, ethylene and diethyl ether, with trace amount of other products, which was facile to study the effect of acid sites on the product distribution. Notably, this may only be true in the low reaction temperature $\left(200^{\circ} \mathrm{C}\right.$ in this work). At higher reaction temperature, some other products were formed, i.e. propene, butene, paraffins, and aromatics [62]. It was also reported that the weak acid sites of ZSM- 5 benefited the ethylene production $[18,74]$. But this is the first time to propose the relation between weak acid sites of ZSM-5 catalysts and corresponding ethylene production.

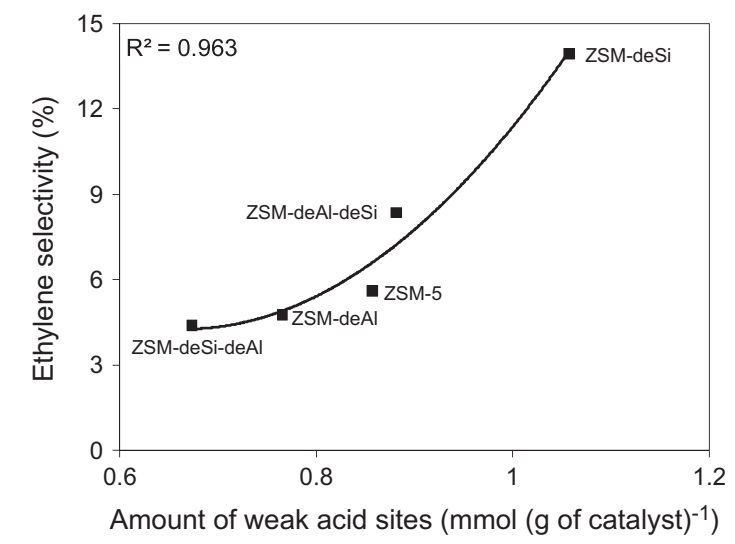

Fig. 12. Relationship between the steady-state ethylene selectivity and the amount of weak acid sites for parent and post-treated ZSM-5 catalysts. 
To build up the correlations between steady-state ethylene selectivity and other acidity features, such as the total acid sites (see Fig. S3 in Supplementary information SI-4), strong acid sites (see Fig. S4 in Supplementary information SI-4), and the correlation between the steady-state ethanol conversion (after time-onstream of $2.33 \mathrm{~h}$ ) and the amount of strong acid sites (see Fig. S5 in Supplementary information SI-4), our best efforts yielded no convincing results. This might be an indication that the ethylene formation may not be directly related to these factors under present reaction conditions.

When we tested the catalytic dehydration of ethanol over pure siliceous Silicalite-1, we obtained a very low activity (ca. $2 \%$ ethanol conversion), with diethyl ether being the only product (see Fig. S6 in Supplementary information SI-5). Clearly, the very weak acid sites on Silicalite- 1 were mainly $\mathrm{Si}-\mathrm{OH}$, since there was no $\mathrm{Al}$ atom in the framework. This indicated that the Brønsted acid sites (Al atom involved) indeed played a key role in the conversion of ethanol and formation of ethylene. Moreover, as mentioned above, this also proposed that the increased weak acid sites after desilication may also include $\mathrm{Al}-\mathrm{OH}-\mathrm{Si}$ groups with weak acidity, except for the silanol generated.

\subsubsection{Stability of the catalysts}

The post-treatments, i.e. desilication, dealumination or their combinations, of ZSM-5 may partly lead to the deterioration of the structure, which may sometimes affect its stability in catalytic reactions. The catalyst with the highest ethylene yield, ZSM-deSi, and the parent ZSM-5 catalyst were selected to evaluate their stability in the dehydration of ethanol. As can be seen in Fig. S7 (see Supplementary information SI-6), the conversion capacity of ethanol of the two catalysts did not change dramatically during the time-on-stream of around $12 \mathrm{~h}$; therefore, the deactivation of the catalysts from coke could be ignored. The ethylene selectivity was also quite stable during the longer reaction time. This result suggested that the post-treatment (such as desilication) may improve the ethylene yield of the catalyst without sacrificing its stability.

\subsection{Computational part}

\subsubsection{Acid model}

It was reported that the catalytic activity was more reasonably attributed to a Brønsted acid site mechanism, and Lewis acid site seemed to have little contribution to the conversion of ethanol [11]. Therefore, B-ZSM-5 and Al-ZSM-5 models were used to represent two zeolites with varied Brønsted acidity (Fig. 13) and to study the effect of zeolite acidity strength on the reaction activity and product selectivity. Deprotonation energy (DPE), which was defined as the energy required to remove the acidic proton from the acid site to form an anionic conjugate base $\left(\mathrm{AH} \rightarrow \mathrm{H}^{+}+\mathrm{A}^{-}\right)$, was a criterion to evaluate the intrinsic acid strength of Brønsted acid site for solid acid catalysts [78,79]. In principle, a smaller
DPE value corresponds to a stronger acidity. Table 3 displayed the DPE and main geometry parameters of Al-ZSM-5 Brønsted acid model and B-doped one. It can be seen that the intrinsic acidity of Al-doped model (DPE $=299.76 \mathrm{kcal} / \mathrm{mol}$ ) was stronger than B-doped one $(\mathrm{DPE}=313.52 \mathrm{kcal} / \mathrm{mol})$, with the $\mathrm{O} 1-\mathrm{H} 1$ bond lengths decreased from $0.967 \AA$ A to $0.964 \AA$ A. In the following section, the two acid models will be used to investigate the influence of acid strength on the reactivity of ethanol to ethylene and diethyl ether.

\subsubsection{Influence of acid strength on reactivity of ethanol to ethylene}

As depicted in Scheme S1 (see Supplementary information SI7 ), one ethanol molecule was initially adsorbed on the Brønsted acid site, and then, an ethoxide species was formed through an ethyl carbenium transition state (step 1). Subsequently, the ethoxide species underwent a deprotonation process, losing a proton to the Brønsted acid site and forming an ethylene molecule (step 2), and the related adsorbed structures and transition states for the ethanol transformations were shown in Figs. 14 and 15, respectively. Fig. 15(a) and (b) illustrated the optimized transition states for the ethoxide species (step 1) and ethylene formation (step 2), respectively. The ethyl group of the transition state for step 1 had characteristics of a carbenium ion $(0.799|\mathrm{e}|)$ to interact with the zeolite framework, and $\mathrm{C} 1-04$ bond length of ethanol was elongated to $2.069 \AA$ and resulted in water molecule formation from the interaction of the hydroxyl group and Brønsted acidic proton (Fig. 15(a)). While to the transition state for step 2 for ethylene formation, the $\mathrm{C} 1-\mathrm{C} 2$ bond length of ethoxide species was decreased to $1.388 \AA$, which apparently was indicative of the formation of $\mathrm{C} 1=\mathrm{C} 2$ double bond (1.339 $\AA$ ). Simultaneously, the proton was partially transferred from the methyl group of ethoxide to the zeolite framework, which was evidenced by the $\mathrm{O} 1-\mathrm{H} 2$ distance decreasing from $2.453 \AA$ (in ethoxide, as shown in Fig. 14(b)) to $1.429 \AA$ (in transition state, see Fig. 15(b)). The activation energies were 38.2 and $35.4 \mathrm{kcal} / \mathrm{mol}$ for step 1 and step 2 over Al-ZSM-5 (Table 4), respectively; therefore, the formation of ethoxide intermediate was the rate-determining step (RDS) for producing ethylene. It is well known that the Brønsted acidic strength plays a crucial role in the acid-catalyzed reactions, and the reactivity and reaction selectivity are strongly determined by the acid strength of the catalysts. As demonstrated in Table 4, the activation energies of step 1 and step 2 were sensitive to the

\section{Table 3}

Deprotonation energy (DPE, kcal/mol), Mulliken charge for acidic proton (H1 (|e|)), and main geometry parameters (Bond length, Å; Angle, deg) of isolated Al-doped and B-doped 8T Brønsted acid site models.

\begin{tabular}{lllllll}
\hline Models & Energy & Charge & \multicolumn{5}{c}{ Geometry parameters } \\
\cline { 4 - 7 } & $\mathrm{DPE}$ & $\mathrm{Q}_{\mathrm{H} 1}$ & $r_{\mathrm{O} 1-\mathrm{H} 1}$ & $r_{\mathrm{Al} / \mathrm{B}-\mathrm{O} 1}$ & $r_{\mathrm{Si}-\mathrm{O} 1}$ & $<\mathrm{Al} / \mathrm{BO} 1 \mathrm{Si}>$ \\
\hline Al-ZSM-5 & 299.76 & 0.406 & 0.967 & 1.830 & 1.655 & 121.55 \\
$\mathrm{~B}-\mathrm{ZSM}-5$ & 313.52 & 0.380 & 0.964 & 1.800 & 1.640 & 132.58 \\
\hline
\end{tabular}

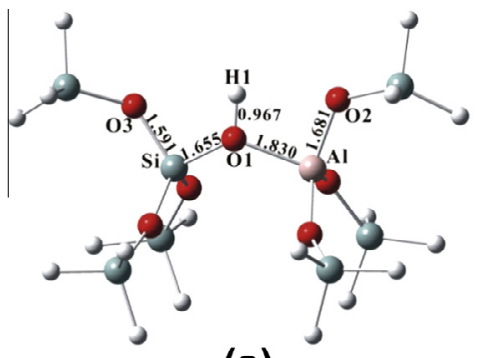

(a)

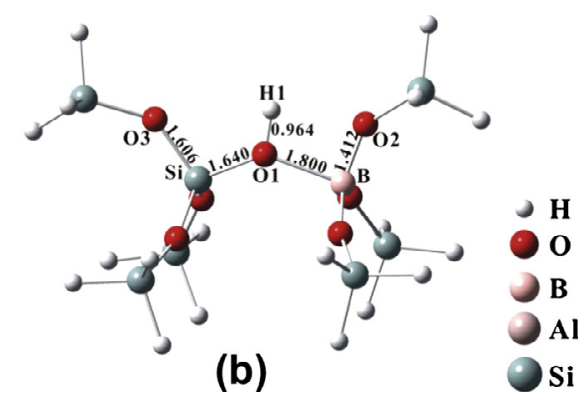

(b)

Fig. 13. Representations of the $8 \mathrm{~T}$ Al-ZSM-5 (a) and B-ZSM-5 (b) cluster model. 


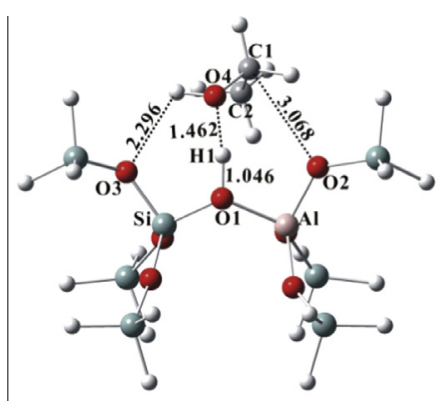

(a)

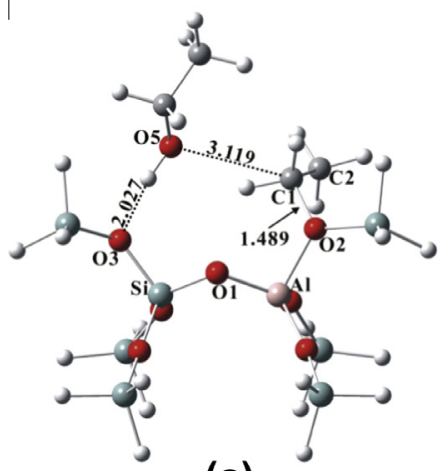

(c)

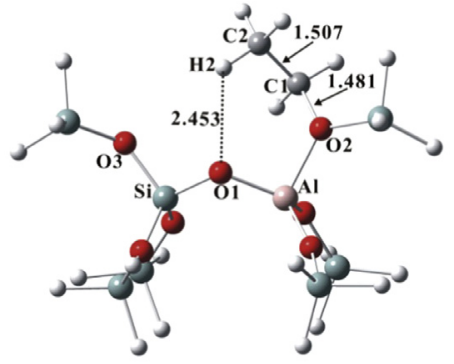

(b)

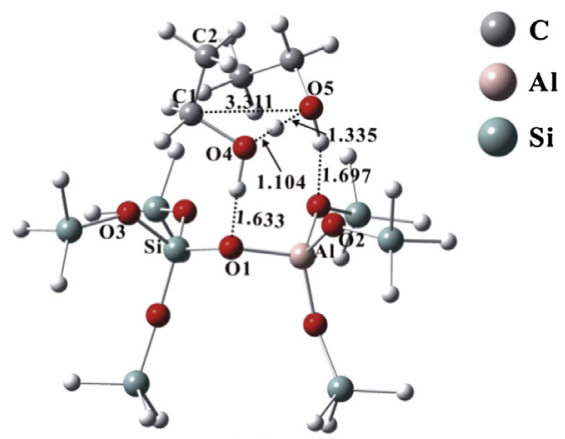

(d)

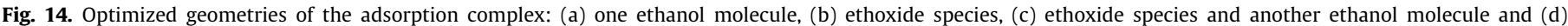
coadsorption of two ethanol molecules on Al-ZSM-5.

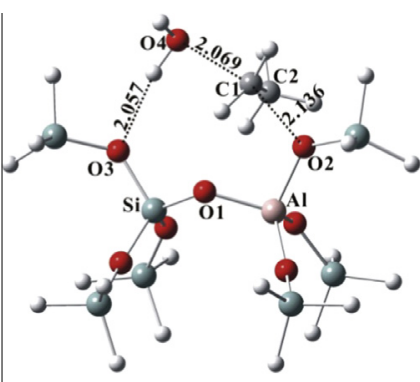

(a)

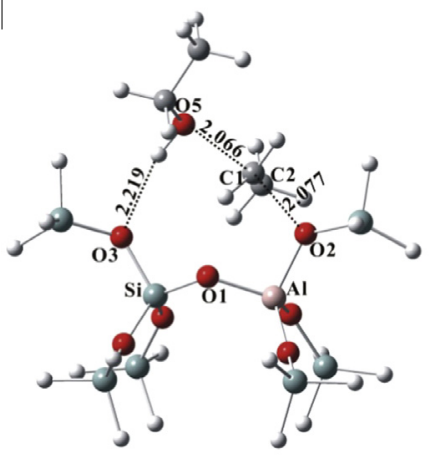

(c)

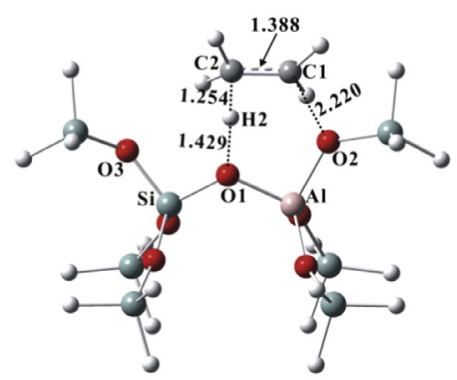

(b)

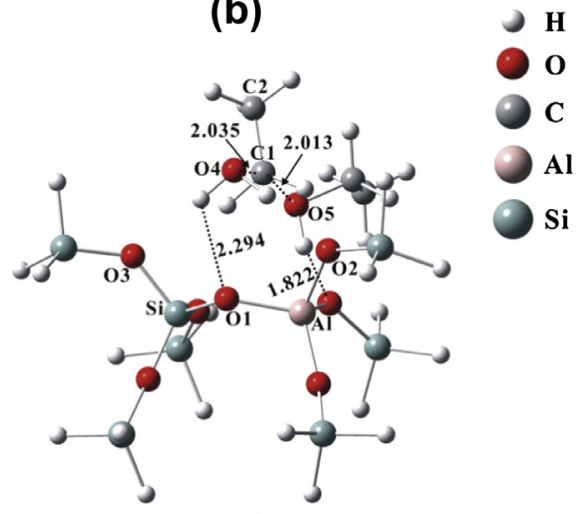

(d)

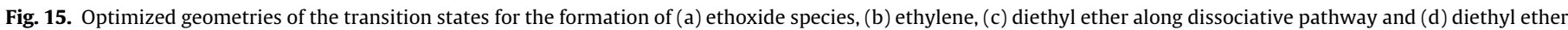
along associative pathway on Al-ZSM-5.

acid strength for the ethylene formation. The activation energies were increased to 45.0 and $44.7 \mathrm{kcal} / \mathrm{mol}$ for step 1 and step 2, respectively, when ethanol was catalyzed by the weaker acidic
B-ZSM-5 zeolite. They were ca. 7 and $10 \mathrm{kcal} / \mathrm{mol}$ higher than those of stronger acidic Al-ZSM-5, thus apparently indicating a relative lower activity on the B-ZSM-5 zeolites. 
Table 4

Activation energies $(\mathrm{kcal} / \mathrm{mol})$ for the ethanol to ethylene and diethyl ether reactions on Brønsted acid site of Al- and B-ZSM-5 models.

\begin{tabular}{|c|c|c|c|c|c|}
\hline \multirow[t]{3}{*}{ Reaction path } & & \multicolumn{4}{|c|}{ Activated barrier $\left(E_{\text {act }}\right)$} \\
\hline & & \multicolumn{2}{|l|}{ Step 1} & \multicolumn{2}{|l|}{ Step 2} \\
\hline & & Al-ZSM-5 & B-ZSM-5 & Al-ZSM-5 & B-ZSM-5 \\
\hline Ethylene & & 38.2 & 45.0 & 35.4 & 44.7 \\
\hline \multirow[t]{2}{*}{ Diethyl ether } & Dissociative & 38.2 & 45.0 & 23.0 & 33.8 \\
\hline & Associative & 31.0 & 40.7 & 1 & l \\
\hline
\end{tabular}

\subsubsection{Influence of acid strength on reactivity of ethanol to diethyl ether}

Two pathways have been proposed for the transformation of alcohol to ether: the dissociative and associative mechanisms (Scheme S2, see Supplementary information SI-7) [80]. For the dissociative pathway, the first step (step 1) was the formation of ethoxide species, which was similar to step 1 for the ethylene generation. Subsequently, the ethoxide species acted as an ethylating agent and reacted with a second ethanol molecule (step 2). The associative pathway was defined by coadsorption of two ethanol molecules, which reacted and formed diethyl ether directly [80,81]. Fig. 15(c) and (d) depicted the optimized transition states for ethanol to diethyl ether reaction catalyzed by Brønsted acid sites along the dissociative and associative pathway, respectively. As for the dissociative pathway, the transition state for the ethoxide formation (step 1, see Fig. 15(a)) was discussed in the above section. The transition state of step 2 for the diethyl ether formation clearly indicated the spatial proximity of carbon in the ethoxide and oxygen in another ethanol (2.066 $\AA$ ). At the same time, the C1-O2 bond (1.481 A, Fig. 14(b)) in ethoxide was increased to $2.077 \AA$ (Fig. 15(c)), which suggested the dissociation of the C1-O2 bond from the zeolite framework. As shown in Fig. 15(d), the distance of $\mathrm{C} 1-\mathrm{O} 5$ between the carbon atom (C1) in ethanol and oxygen atom (05) in another ethanol was $2.013 \AA$, and significantly shorter than that in the co-adsorbed state $(3.311 \AA$, Fig. 14(d)), indicating that the diethyl ether would be formed through the associative pathway, in accordance with previous study on ethanol dehydration over acidic zeolites [81] or 2-butanol dehydration over polyoxometalate [80]. The activation energies for two mechanisms catalyzed by Al-ZSM-5 and B-ZSM-5 zeolites were listed in Table 4. For the dissociative mechanism on Al-ZSM-5 model, the activation energies for step 1 and step 2 were 38.2 and $23.0 \mathrm{kcal} / \mathrm{mol}$, respectively. It is much similar to the ethylene production catalyzed by the zeolite as aforementioned that the weaker Brønsted acidity will result in relatively high barriers for the ethanol transformation and diethyl ether formation. The activation energies were increased to 45.0 and $33.8 \mathrm{kcal} / \mathrm{mol}$ on B-ZSM-5 zeolite, which were ca. 7 and $11 \mathrm{kcal} / \mathrm{mol}$ higher than Al-ZSM-5. The calculated results demonstrated again that stronger acidity could significantly improve the reactivity of the reactions studied. Note that the activation energies were 31.0 and $40.7 \mathrm{kcal} / \mathrm{mol}$ for the diethyl ether formations through the associative pathway catalyzed by $\mathrm{Al}$ and B-ZSM-5 zeolites as listed in Table 4, respectively.

Apparently, the activation barrier of the rate-determining step for the formation of diethyl ether was relatively lower than that of ethylene both on the Al-ZSM-5 and B-ZSM-5 zeolites (Table 4), no matter which pathway for the diethyl ether formation. Therefore, the formation of diethyl ether was always favored, even the reaction mechanism and acid strength do not matter. It is noteworthy that the associative pathway for the diethyl ether formations needs relatively high ethanol concentration and two ethanol molecules co-adsorbed on the same Brønsted acid site. Very low ethanol partial pressure was used in our experiment; therefore, such associative pathway may be excluded.
As mentioned above, ethoxide species bonded to zeolite framework through ethanol dehydration reaction will be generated initially under our catalytic conditions with very low ethanol partial pressure. It is well accepted that the ethoxide species is an important intermediate which can be directly dehydrogenated to ethylene or react with another adsorbed ethanol molecule to result in diethyl ether formation. Therefore, the reaction selectivity is strongly determined by their relative activation energies.

In this case, the ethoxide species will be formed initially by the adsorbed ethanol molecule, subsequently generating an ethylene or a diethyl ether molecule with another ethanol. The formation of diethyl ether was still favored, no matter which acid (the stronger Al-ZSM-5 or the weaker B-ZSM-5) was considered. However, as demonstrated in Table 4, the activation energies for the ethylene generation (step 2) were 35.4 and $44.7 \mathrm{kcal} / \mathrm{mol}$ on Al-ZSM-5 and B-ZSM-5, respectively, while the corresponding barriers were 23.0 and $33.8 \mathrm{kcal} / \mathrm{mol}$ for diethyl ether (step 2). The activation energies were reduced by 9.3 and $10.8 \mathrm{kcal} / \mathrm{mol}$ for the ethylene and diethyl ether formations with zeolite acidity increasing from B-ZSM-5 to Al-ZSM-5. Comparing to the diethyl ether formation $(10.8 \mathrm{kcal} / \mathrm{mol})$, a relatively smaller difference $(9.3 \mathrm{kcal} / \mathrm{mol})$ in the activation energies of the ethylene formation was present, which was obviously indicative that ethylene production was not as sensitive as the diethyl ether formation. In other words, if the Brønsted acidic strength of zeolite catalyst was increased from weak acidity (B-ZSM-5) to strong acidity (Al-ZSM-5), the reaction rate of diethyl ether formation will be considerably enhanced, nevertheless, which was not such obvious for the ethylene formation for relative narrower barrier gap with the change of the zeolite acidities. Therefore, one may conclude from the transition-state theory that the selectivity for the diethyl ether formation tended to deteriorate with decreasing catalytic Brønsted acidity. On the contrary, the percentage of ethylene production will be relative higher on the weaker acid site, even if the diethyl ether formation was still favored. Our theoretical results were in excellent match with the experimental data.

Furthermore, the acidic sensitivity of the catalyzed reactions could be exposed by the ionic character of the TS as well $[22,25]$. In a recent work, the ionic characters of TS have been successfully applied to explain the acidic sensitivity of the alkenes protonation, alkanes isomerization and activations [25]. Table 5 listed the natural charges of the organic fragments for the transition states of the two competitive reactions. The natural charges of the TS (step 2) were $0.784 \mathrm{le} \mid$ for ether formation and $0.697 \mathrm{le}$ for ethylene production over Al-ZSM-5 when the reactions followed the dissociative mechanisms. Even though for the associative pathways for the ethanol to diethyl ether, the natural charge $0.895|\mathrm{e}|$ of the TS for ether formation was still larger than those $(0.799|\mathrm{e}|$ and $0.697|\mathrm{e}|$ ) of ethylene formations catalyzed by Al-ZSM-5. Compared with ethylene formation, the TS of ether yielding possessed more ionic character which resulted in more sensitive to the acid strength. Therefore, the reactivity of the ether formation would decrease more obviously on the weak acid site and accordingly the percentage of ethylene yield would increase, which

Table 5

Natural charge (|e|) on the hydrocarbon fragments of the transition state (TS) for the ethanol to ethylene and diethyl ether reactions on Brønsted acid site of Al- and BZSM-5 models.

\begin{tabular}{|c|c|c|c|c|c|}
\hline \multirow[t]{3}{*}{ Reaction path } & & \multicolumn{4}{|c|}{ Natural charge } \\
\hline & & \multicolumn{2}{|l|}{ Step 1} & \multicolumn{2}{|l|}{ Step 2} \\
\hline & & Al-ZSM-5 & B-ZSM-5 & Al-ZSM-5 & B-ZSM-5 \\
\hline Ethylene & & 0.799 & 0.790 & 0.697 & 0.671 \\
\hline \multirow[t]{2}{*}{ Diethyl ether } & Dissociative & 0.799 & 0.790 & 0.784 & 0.772 \\
\hline & Associative & 0.895 & 0.877 & 1 & 1 \\
\hline
\end{tabular}


supported the proposed catalytic mechanism derived from the activation energy.

\section{Conclusions}

In conclusion, the relation between weak acid sites of acidic ZSM-5 catalysts and ethylene selectivity has been revealed during the ethanol dehydration reaction on the basis of experimental results. Post-treatments of ZSM-5 may finely tune the amounts of weak and strong acid sites in the zeolites, which would considerably affect the ethylene and diethyl ether production. The acidity strength played a crucial role on the product distribution for ethanol conversion over ZSM-5 catalysts, and the higher selectivity toward ethylene was associated with the increasing weak acidity observed on these post-treated catalysts, which was also confirmed by theoretical calculations.

\section{Acknowledgments}

The project was sponsored by "100 Talents" program of Chinese Academy of Sciences (Grant KJCX2-EW-H05), the Natural Science Foundation of China (Grant No. 21173255), and Doctoral Fund of Shandong Province (BS2013CL029).

\section{Appendix A. Supplementary material}

Supplementary data associated with this article can be found, in the online version, at http://dx.doi.org/10.1016/j.jcat.2014.02.003.

\section{References}

[1] O.J. Sanchez, C.A. Cardona, Bioresour. Technol. 99 (2008) 5270.

[2] R. Levanmao, T.M. Nguyen, G.P. McLaughlin, Appl. Catal. 48 (1989) 265.

[3] C.J. Pereira, Science 285 (1999) 670.

[4] M. Zhang, Y. Yu, Ind. Eng. Chem. Res. 52 (2013) 9505.

[5] D. Fan, D.-J. Dai, H.-S. Wu, Materials 6 (2013) 101.

[6] J.F. Haw, W.G. Song, D.M. Marcus, J.B. Nicholas, Acc. Chem. Res. 36 (2003) 317.

[7] W. Wang, M. Hunger, Acc. Chem. Res. 41 (2008) 895.

[8] M. Choi, K. Na, J. Kim, Y. Sakamoto, O. Terasaki, R. Ryoo, Nature 461 (2009) 246

[9] R. Levanmao, T.M. Nguyen, J. Yao, Appl. Catal. 61 (1990) 161.

[10] F.F. Madeira, K. Ben Tayeb, L. Pinard, H. Vezin, S. Maury, N. Cadran, Appl. Catal. A-Gen. 443 (2012) 171.

[11] W.R. Moser, R.W. Thompson, C.C. Chiang, H. Tong, J. Catal. 117 (1989) 19.

[12] Y. Han, C. Lu, D. Xu, Y. Zhang, Y. Hu, H. Huang, Appl. Catal. A-Gen. 396 (2011) 8.

[13] J.N. Kondo, K. Ito, E. Yoda, F. Wakabayashi, K. Domen, J. Phys. Chem. B 109 (2005) 10969.

[14] J.N. Kondo, D. Nishioka, H. Yamazaki, J. Kubota, K. Domen, T. Tatsumi, J. Phys Chem. C 114 (2010) 20107.

[15] K. Na, M. Choi, R. Ryoo, Micropor. Mesopor. Mater. 166 (2013) 3.

[16] S. Ivanova, E. Vanhaecke, L. Dreibine, B. Louis, C. Pham, C. Pham-Huu, Appl Catal. A-Gen. 359 (2009) 151.

[17] A.G. Gayubo, A. Alonso, B. Valle, A.T. Aguayo, J. Bilbao, Appl. Catal. B-Environ. 97 (2010) 299.

[18] Q. Sheng, K. Ling, Z. Li, L. Zhao, Fuel Process. Technol. 110 (2013) 73.

[19] X.B. Zheng, P. Blowers, J. Phys. Chem. A 110 (2006) 2455.

[20] E. Kassab, M. Castella-Ventura, Y. Akacem, J. Phys. Chem. C 113 (2009) 20388.

[21] S.R. Blaszkowski, M.A.C. Nascimento, R.A. vanSanten, J. Phys. Chem. 100 (1996) 3463.

[22] H. Fang, A. Zheng, S. Li, J. Xu, L. Chen, F. Deng, J. Phys. Chem. C 114 (2010) 10254.

[23] Y. Chu, B. Han, A. Zheng, F. Deng, J. Phys. Chem. C 116 (2012) 12687.

[24] A. Zheng, S.-B. Liu, F. Deng, Micropor. Mesopor. Mater. 121 (2009) 158.

[25] Y. Chu, B. Han, H. Fang, A. Zheng, F. Deng, Micropor. Mesopor. Mater. 151 (2012) 241.

[26] A. Zheng, H. Zhang, L. Chen, Y. Yue, C. Ye, F. Deng, J. Phys. Chem. B 111 (2007) 3085.

[27] P.G. Moses, J.K. Norskov, ACS Catal. 3 (2013) 735.

[28] G.J. Kramer, R.A. Vansanten, C.A. Emeis, A.K. Nowak, Nature 363 (1993) 529.

[29] G.J. Kramer, R.A. Van Santen, J. Am. Chem. Soc. 117 (1995) 1766.
[30] J.C. Groen, T. Bach, U. Ziese, A. Donk, K.P. de Jong, J.A. Moulijn, J. Perez-Ramirez, J. Am. Chem. Soc. 127 (2005) 10792.

[31] N. Danilina, F. Krumeich, S.A. Castelanelli, J.A. van Bokhoven, J. Phys. Chem. C 114 (2010) 6640.

[32] H. Xin, A. Koekkoek, Q. Yang, R. van Santen, C. Li, E.J.M. Hensen, Chem. Commun. (2009) 7590.

[33] H. Vankoningsveld, H. Vanbekkum, J.C. Jansen, Acta Crystallogr. Sect. B-Struct. Sci. 43 (1987) 127.

[34] J.-D. Chai, M. Head-Gordon, Phys. Chem. Chem. Phys. 10 (2008) 6615.

[35] J. Van der Mynsbrugge, M. Visur, U. Olsbye, P. Beato, M. Bjorgen, V. Van Speybroeck, S. Svelle, J. Catal. 292 (2012) 201.

[36] J. Van der Mynsbrugge, K. Hemelsoet, M. Vandichel, M. Waroquier, V. Van Speybroeck, J. Phys. Chem. C 116 (2012) 5499.

[37] A.J.J. Koekkoek, H. Xin, Q. Yang, C. Li, E.J.M. Hensen, Micropor. Mesopor. Mater. 145 (2011) 172.

[38] S. Li, S.-J. Huang, W. Shen, H. Zhang, H. Fang, A. Zheng, S.-B. Liu, F. Deng, J. Phys. Chem. C 112 (2008) 14486.

[39] Z. Yu, A. Zheng, Q. Wang, L. Chen, J. Xu, J.-P. Amoureux, F. Deng, Angew. Chem. Int. Ed. 49 (2010) 8657.

[40] A. Bonilla, D. Baudouin, J. Perez-Ramirez, J. Catal. 265 (2009) 170.

[41] S. Ramdas, J. Klinowski, Nature 308 (1984) 521.

[42] G. Engelhardt, S. Luger, J.C. Buhl, J. Felsche, Zeolites 9 (1989) 182.

[43] Y. Liu, H. Nekvasil, J. Tossell, J. Phys. Chem. A 109 (2005) 3060.

[44] D.H. Olson, G.T. Kokotailo, S.L. Lawton, W.M. Meier, J. Phys. Chem. 85 (1981) 2238.

[45] J.A. van Bokhoven, A.L. Roest, D.C. Koningsberger, J.T. Miller, G.H. Nachtegaal, A.P.M. Kentgens, J. Phys. Chem. B 104 (2000) 6743.

[46] P. Sazama, Z. Sobalik, J. Dedecek, I. Jakubec, V. Parvulescu, Z. Bastl, J. Rathousky, H. Jirglova, Angew. Chem. Int. Ed. 52 (2013) 2038.

[47] S. Li, A. Zheng, Y. Su, H. Zhang, L. Chen, J. Yang, C. Ye, F. Deng, J. Am. Chem. Soc. 129 (2007) 11161.

[48] M. Choi, H.S. Cho, R. Srivastava, C. Venkatesan, D.-H. Choi, R. Ryoo, Nat. Mater. 5 (2006) 718.

[49] R.J. Gorte, Catal. Today 28 (1996) 405.

[50] F. Lonyi, J. Valyon, Micropor. Mesopor. Mater. 47 (2001) 293.

[51] I. Craciun, M.-F. Reyniers, G.B. Marin, J. Catal. 294 (2012) 136.

[52] F. Collignon, G. Poncelet, J. Catal. 202 (2001) 68.

[53] M. Anilkumar, W.F. Hoelderich, J. Catal. 293 (2012) 76.

[54] G.D. Yadav, N.P. Ajgaonkar, A. Varma, J. Catal. 292 (2012) 99.

[55] L.A. Perea, T. Wolff, P. Veit, L. Hilfert, F.T. Edelmann, C. Hamel, A. SeidelMorgenstern, J. Catal. 305 (2013) 154.

[56] S. Zhu, X. Gao, Y. Zhu, Y. Zhu, H. Zheng, Y. Li, J. Catal. 303 (2013) 70.

[57] K. Bouchmella, P.H. Mutin, M. Stoyanova, C. Poleunis, P. Eloy, U. Rodemerck, E.M. Gaigneaux, D.P. Debecker, J. Catal. 301 (2013) 233.

[58] V.V. Ordomsky, J. van der Schaaf, J.C. Schouten, T.A. Nijhuis, J. Catal. 287 (2012) 68.

[59] X.L. Zhu, L.L. Lobban, R.G. Mallinson, D.E. Resasco, J. Catal. 271 (2010) 88

[60] X.F. Li, R. Prins, J.A. van Bokhoven, J. Catal. 262 (2009) 257.

[61] G.L. Zhao, J.W. Teng, Z.K. Xie, W.Q. Jin, W.M. Yang, Q.L. Chen, Y. Tang, J. Catal. 248 (2007) 29.

[62] W. Xia, A. Takahashi, I. Nakamura, H. Shimada, T. Fujitani, J. Mol. Catal. AChem. 328 (2010) 114.

[63] A.G. Gayubo, A. Alonso, B. Valle, A.T. Aguayo, J. Bilbao, AICHE J. 58 (2012) 526.

[64] L.G. Possato, R.N. Diniz, T. Garetto, S.H. Pulcinelli, C.V. Santilli, L. Martins, J. Catal. 300 (2013) 102.

[65] R.J. Gorte, J. Catal. 75 (1982) 164.

[66] E.E. Ibok, D.F. Ollis, J. Catal. 66 (1980) 391.

[67] W.E. Farneth, R.J. Gorte, Chem. Rev. 95 (1995) 615.

[68] W.R. Moser, C.C. Chiang, R.W. Thompson, J. Catal. 115 (1989) 532.

[69] J.N. Kondo, E. Yoda, H. Ishikawa, F. Wakabayashi, K. Domen, J. Catal. 191 (2000) 275.

[70] M. Maache, A. Janin, J.C. Lavalley, J.F. Joly, E. Benazzi, Zeolites 13 (1993) 419.

[71] J.P. Marques, I. Gener, P. Ayrault, J.C. Bordado, J.M. Lopes, F.R. Ribeiro, M. Guisnet, Micropor. Mesopor. Mater. 60 (2003) 251.

[72] K.K. Ramasamy, Y. Wang, J. Energy Chem. 22 (2013) 65.

[73] V.S. Nayak, V.R. Choudhary, Appl. Catal. 9 (1984) 251.

[74] S.N. Chaudhuri, C. Halik, J.A. Lercher, J. Mol. Catal. 62 (1990) 289.

[75] D. Li, P. Bui, H.Y. Zhao, S.T. Oyama, T. Dou, Z.H. Shen, J. Catal. 290 (2012) 1.

[76] J. Perez-Ramirez, C.H. Christensen, K. Egeblad, C.H. Christensen, J.C. Groen, Chem. Soc. Rev. 37 (2008) 2530.

[77] D. Goto, Y. Harada, Y. Furumoto, A. Takahashi, T. Fujitani, Y. Oumi, M. Sadakane, T. Sano, Appl. Catal. A-Gen. 383 (2010) 89.

[78] H.V. Brand, L.A. Curtiss, L.E. Iton, J. Phys. Chem. 97 (1993) 12773.

[79] U. Eichler, M. Brandle, J. Sauer, J. Phys. Chem. B 101 (1997) 10035.

[80] J. Macht, M.J. Janik, M. Neurock, E. Iglesia, Angew. Chem. Int. Ed. 46 (2007) 7864.

[81] H. Chiang, A. Bhan, J. Catal. 271 (2010) 251. 


\section{Supplementary Information}

Catalytic dehydration of ethanol over post-treated ZSM-5 zeolites

Hongchuan Xin ${ }^{\mathrm{a}, 1}$, Xiangping $\mathrm{Li}^{\mathrm{a}, 1}$, Yuan Fang ${ }^{\mathrm{a}}$, Xianfeng $\mathrm{Yi}{ }^{\mathrm{b}}$, Wenhui Hu ${ }^{\mathrm{a}}$, Yueying Chu ${ }^{\mathrm{b}}$, Feng Zhang ${ }^{\mathrm{a}}$, Anmin Zheng ${ }^{\mathrm{b}, *}$, Hongpeng Zhang ${ }^{\mathrm{a}}$, Xuebing $\mathrm{Li}^{\mathrm{a}, *}$

${ }^{a}$ Key Laboratory of Biofuels, Qingdao Institute of Bioenergy and Bioprocess Technology, Chinese Academy of Sciences, Qingdao 266101, China

${ }^{b}$ Wuhan Center for Magnetic Resonance, State Key Laboratory of Magnetic Resonance and Atomic and Molecular Physics, Wuhan Institute of Physics and Mathematics, Chinese Academy of Sciences, Wuhan 430071, China

* Corresponding authors.

E-mail addresses: zhenganm@wipm.ac.cn (A. Zheng), lixb@qibebt.ac.cn (X. Li).

${ }^{1}$ These authors contributed equally to this paper. 
SI-1 Lattice spacings from XRD data

SI-2 HR-SEM and TEM

SI-3 Effect of diffusion on TPD measurement

SI-4 Correlation between amount of acid sites and ethylene selectivity (or ethanol conversion)

SI-5 Synthesis and catalytic performance of Silicalite-1

SI-6 Stability of the catalysts

SI-7 Influence of acid strength on reactivity of ethanol to ethylene and diethyl ether 


\section{SI-1 Lattice spacings from XRD data}

The lattice spacings of all the five catalysts were calculated from fitted XRD data, and compared with the lattice spacings of a standard ZSM-5 in the database.

Table S1. Average lattice spacings of parent and post-treated ZSM-5 zeolites.

\begin{tabular}{llll}
\hline Catalyst & a-Axis, $\AA$ & b-Axis, $\AA$ & c-Axis, $\AA$ \\
\hline ZSM-5 & 20.1 & 20.1 & 13.4 \\
ZSM-deSi & 20.0 & 20.4 & 13.4 \\
ZSM-deSi-deAl & 19.9 & 17.1 & 16.5 \\
ZSM-deAl & 20.1 & 20.1 & 13.4 \\
ZSM-deAl-deSi & 20.1 & 20.6 & 13.4 \\
ZSM-5-standard & 20.1 & 20.0 & 13.4 \\
\hline
\end{tabular}


SI-2 HR-SEM and TEM

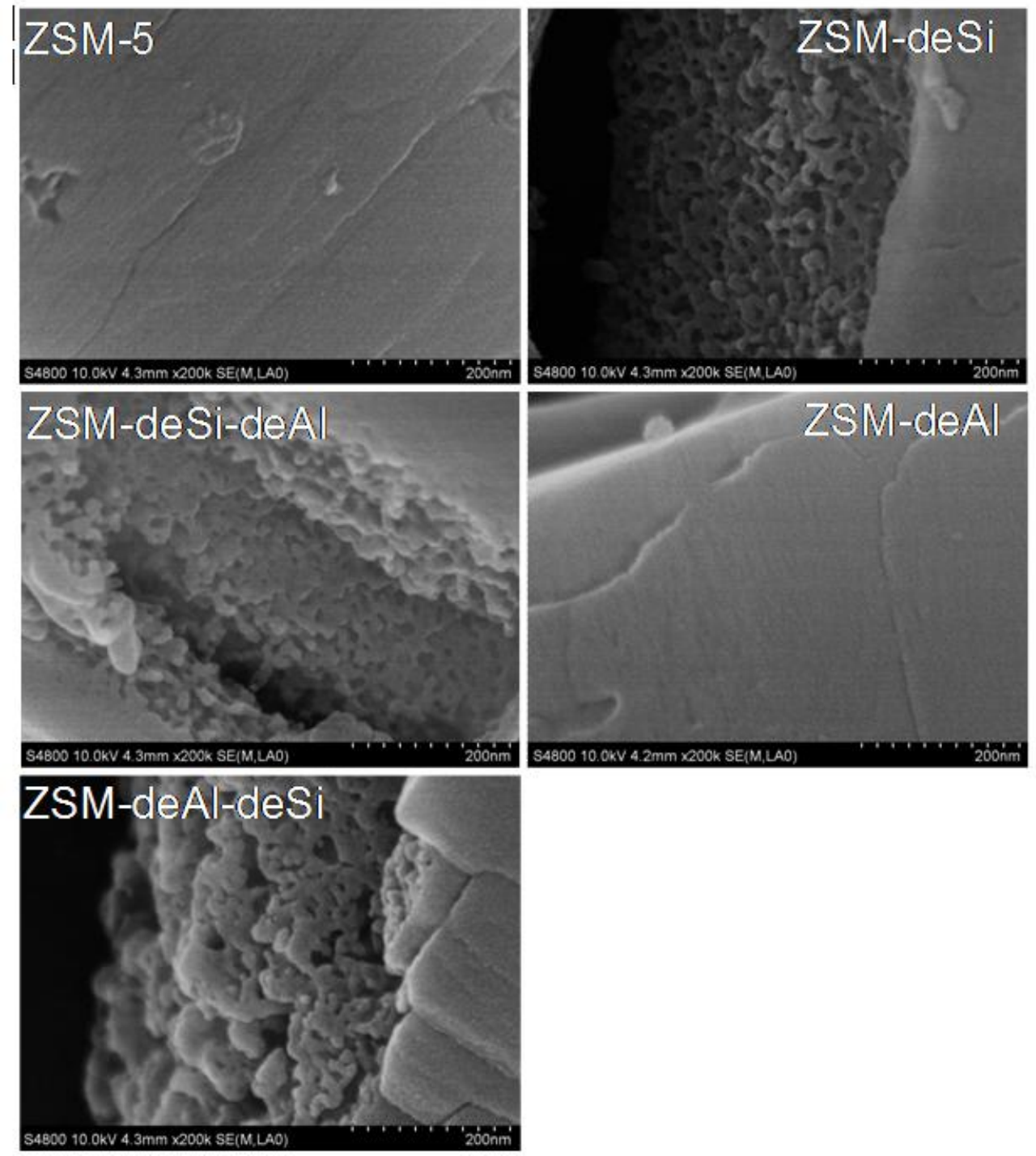

Fig. S1. High-resolution scanning electron micrographs of parent and post-treated ZSM-5 catalysts. 
TEM images were shown in Fig. S2.

ZSM-deAl showed almost no differences from parent ZSM-5, indicating that the dealumination in this study did not destruct the crystal structure substantially. For ZSM-deSi, ZSM-deSi-deAl, and ZSM-deAl-deSi, significant mesoporosity were created, indicating the desilication in this study could modify the porous structures significantly.
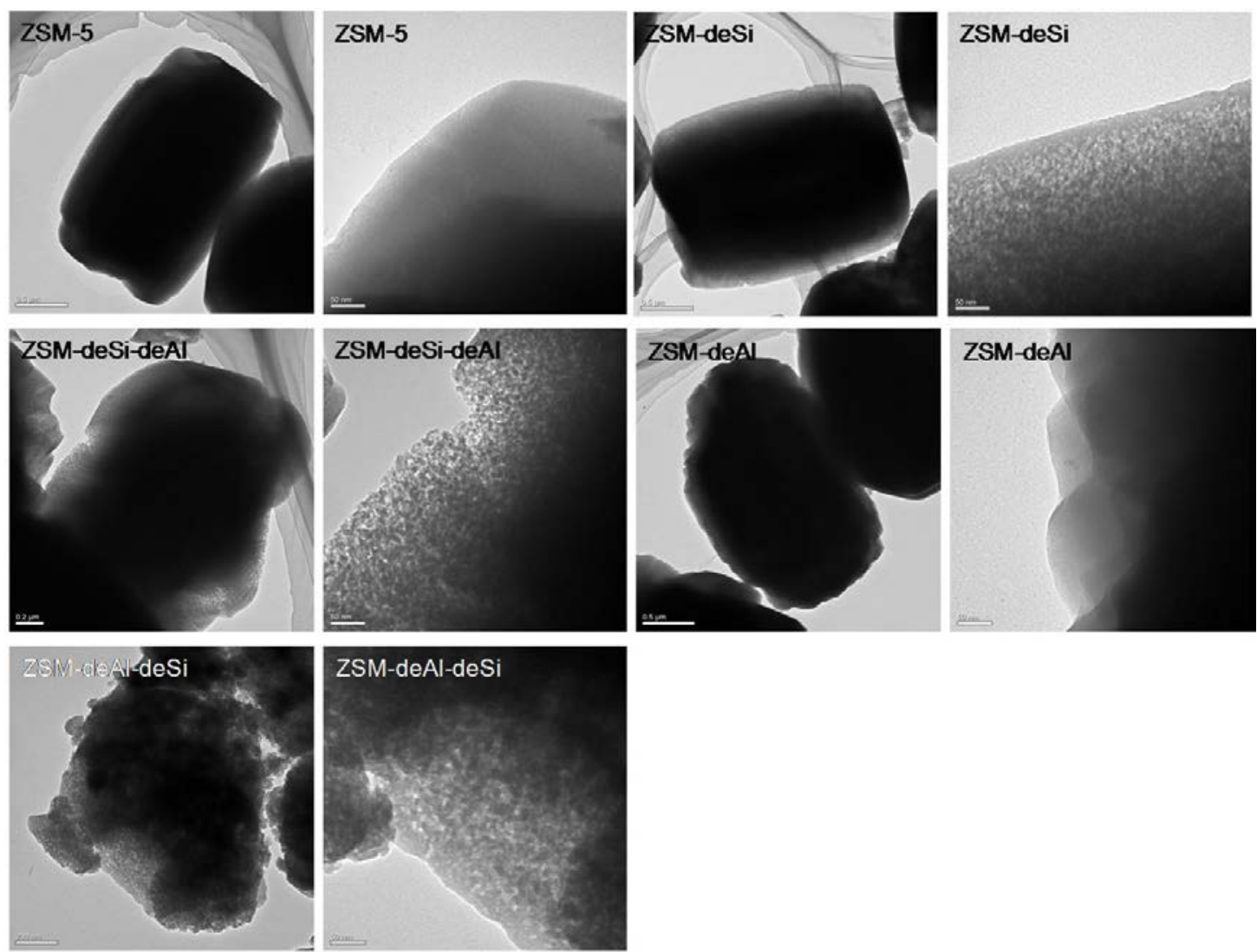

Fig. S2. Transmission electron micrographs of parent and post-treated ZSM-5 catalysts. 


\section{SI-3 Effect of diffusion on TPD measurement}

In order to ensure that the $\mathrm{NH}_{3}$-TPD data were not affected by the lag time for gas to diffuse out of zeolite pores, an analysis was carried out using the criterion of Gorte (J. Catal. 75 (1982) 164) and Ibok and Ollis (J. Catal. 66 (1980) 391). It was suggested that the effect of diffusion limitations could be neglected for a value of less than 0.01 for the group $\frac{\beta l^{2} \varepsilon}{\left(T_{f}-T_{0}\right) D}$, where $\beta$ is the heating rate $(\mathrm{K} / \mathrm{s}), l$ is the width of catalyst slab $(\mathrm{cm}), \varepsilon$ is the porosity $\left(\mathrm{cm}^{3} / \mathrm{cm}^{3}\right), T_{f}$ and $T_{0}$ are the final and initial temperature $(\mathrm{K})$, respectively, and $D$ is the effective diffusivity $\left(\mathrm{cm}^{2} / \mathrm{s}\right)$.

For our experiment, a highest value of $1.9 \times 10^{-6}$ was obtained, and this indicated no diffusion limitations during the $\mathrm{NH}_{3}$-TPD experiments

Table S2. Parameters in the Gorte criterion.

\begin{tabular}{lll}
\hline$\beta$ & Heating rate $(\mathrm{K} / \mathrm{s})$ & 0.17 \\
$l$ & Width of catalyst slab $(\mathrm{cm})$ & 0.025 \\
$\varepsilon$ & Porosity $\left(\mathrm{cm}^{3} / \mathrm{cm}^{3}\right)$ & 0.621 \\
$T_{f}-T_{0}$ & Temperature difference $(\mathrm{K})$ & 500 \\
$D$ & Effective diffusivity & 0.07 \\
\hline
\end{tabular}




\section{SI-4 Correlation between amount of acid sites and ethylene selectivity (or ethanol}

conversion)

We also checked the relation between total acid sites and the ethylene selectivity (Fig. S3). The correlation coefficient was $\mathrm{R}^{2}=0.889$, much lower than $\mathrm{R}^{2}=0.963$ (Fig. 12).

We also checked the effect of strong acid sites on the ethylene selectivity (Fig. S4). The correlation coefficient was 0.618 , also much lower than 0.963 (Fig. 12). We also added the relation between the conversion of ethanol and the amount of strong acid sites in Fig. S5, and the correlation coefficient was only 0.283.

Therefore, we proposed a more convincing correlation between weak acid sites and ethylene selectivity.

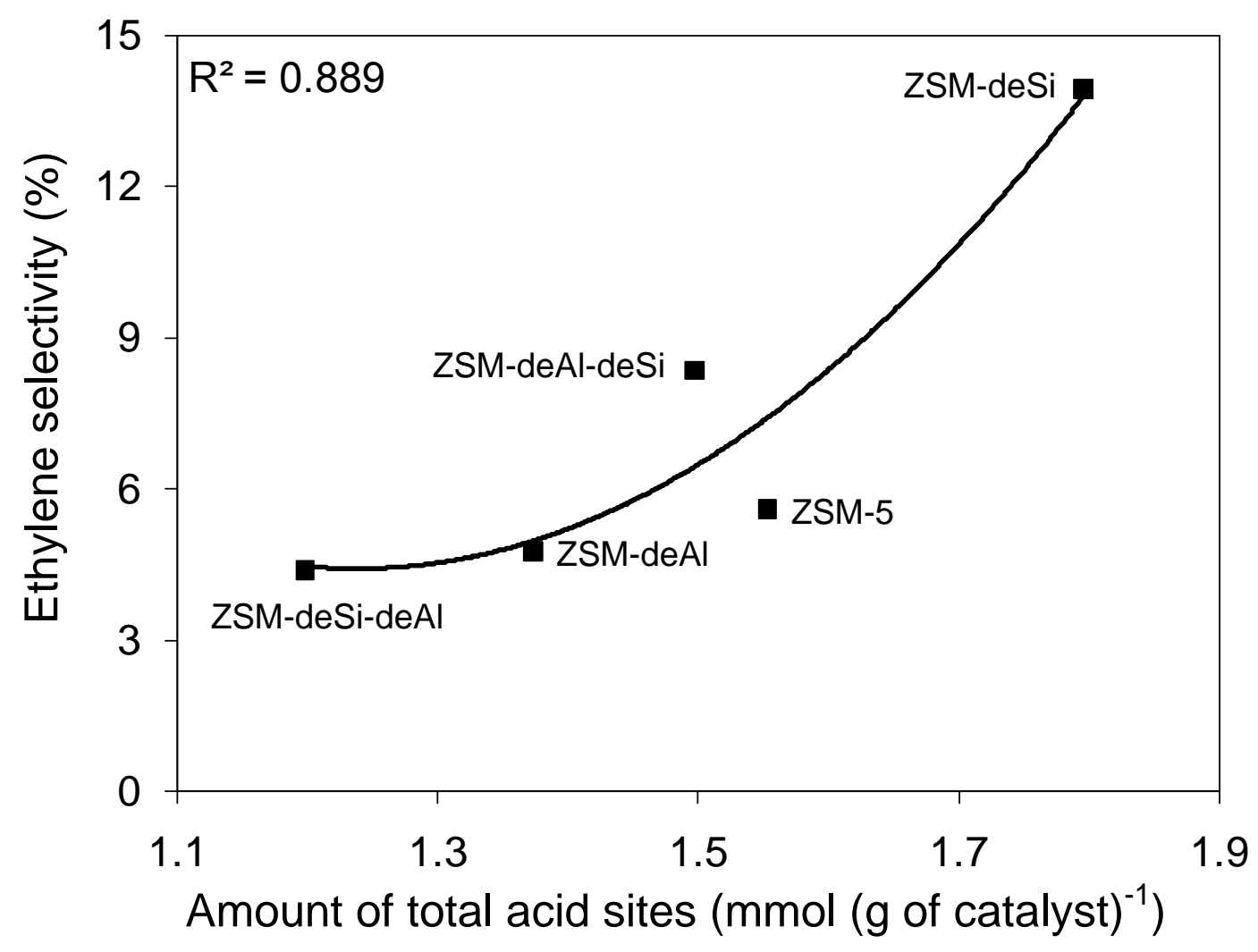

Fig. S3. Relationship between the steady-state ethylene selectivity and the total amount of acid sites for parent and post-treated ZSM-5 catalysts. 


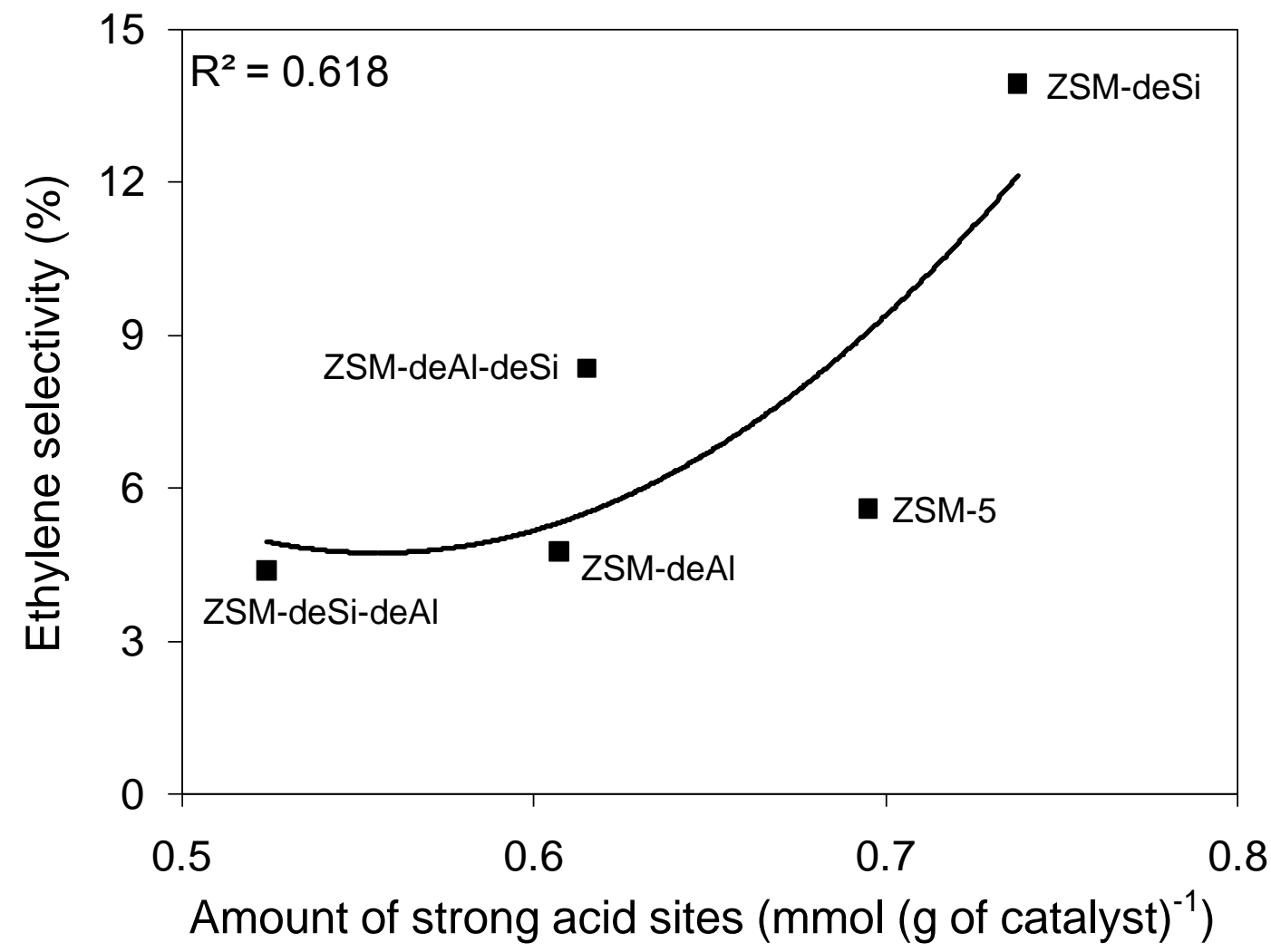

Fig. S4. Relationship between the steady-state ethylene selectivity and the amount of strong acid sites for parent and post-treated ZSM-5 catalysts. 


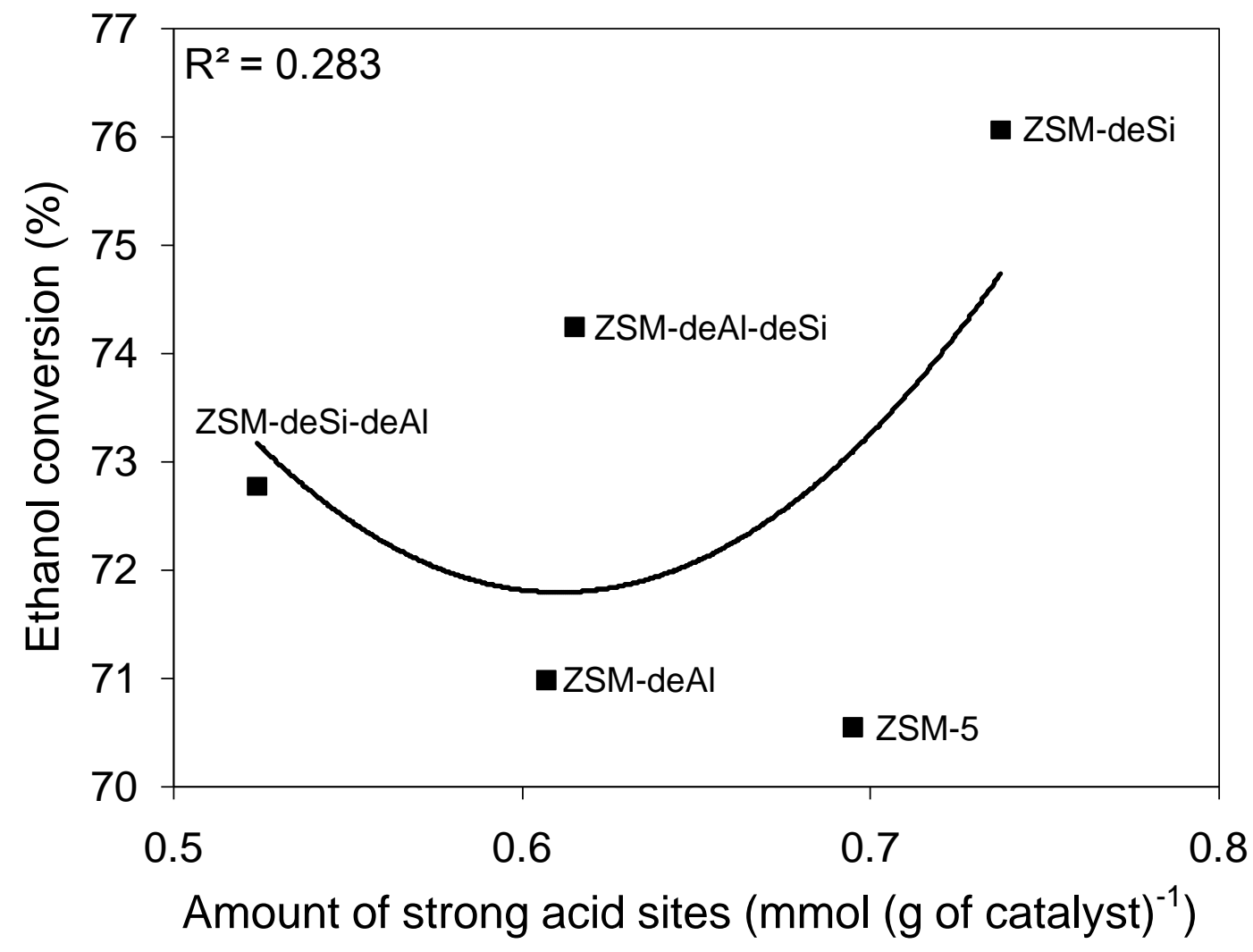

Fig. S5. Relationship between the steady-state conversion of ethanol and the amount of strong acid sites for parent and post-treated ZSM-5 catalysts. 


\section{SI-5 Synthesis and catalytic performance of Silicalite-1}

Synthesis of Silicalite-1:

Silicalite- 1 crystal with the largest dimension of $2 \mu \mathrm{m}$ was synthesized using the method from literature (Langmuir, 29 (2013) 13943). To this end, tetrapropylammonium bromide (TPABr, 99\%, Tianjin Guangfu Fine Chemical Research Institute) and sodium hydroxide ( $\mathrm{NaOH}$, Aladdin) were dissolved in deionized water. Ludox SM-30 (Aldrich) was then added as silicon source. The resulting solution with a composition of $\mathrm{SiO}_{2} / 0.33 \mathrm{TPABr} / 0.17 \mathrm{NaOH} / 333 \mathrm{H}_{2} \mathrm{O}$ was stirred at room temperature for $24 \mathrm{~h}$ and then heated at $175{ }^{\circ} \mathrm{C}$ for 2 days for crystallization. The solid products were washed with deionized water, collected by filtration, and dried in an oven at $100{ }^{\circ} \mathrm{C}$. The synthesized Silicalite- 1 sample was calcined at $550{ }^{\circ} \mathrm{C}$ for $6 \mathrm{~h}$ with a ramping rate of $3{ }^{\circ} \mathrm{C} / \mathrm{min}$ to remove the organic structure directing agent.

Catalytic dehydration over Silicalite-1:

We obtained a very low activity (ca. 2\% ethanol conversion) and no ethylene formation in the product (only diethyl ether formed) (Fig. S6). Clearly, the very weak acid sites on Silicalite-1 were mainly $\mathrm{Si}-\mathrm{OH}$, since there was no $\mathrm{Al}$ atom in the framework. This indicated that the strong Brønsted acid sites (Al atom involved) indeed played a key role in the conversion of ethanol and formation of ethylene.

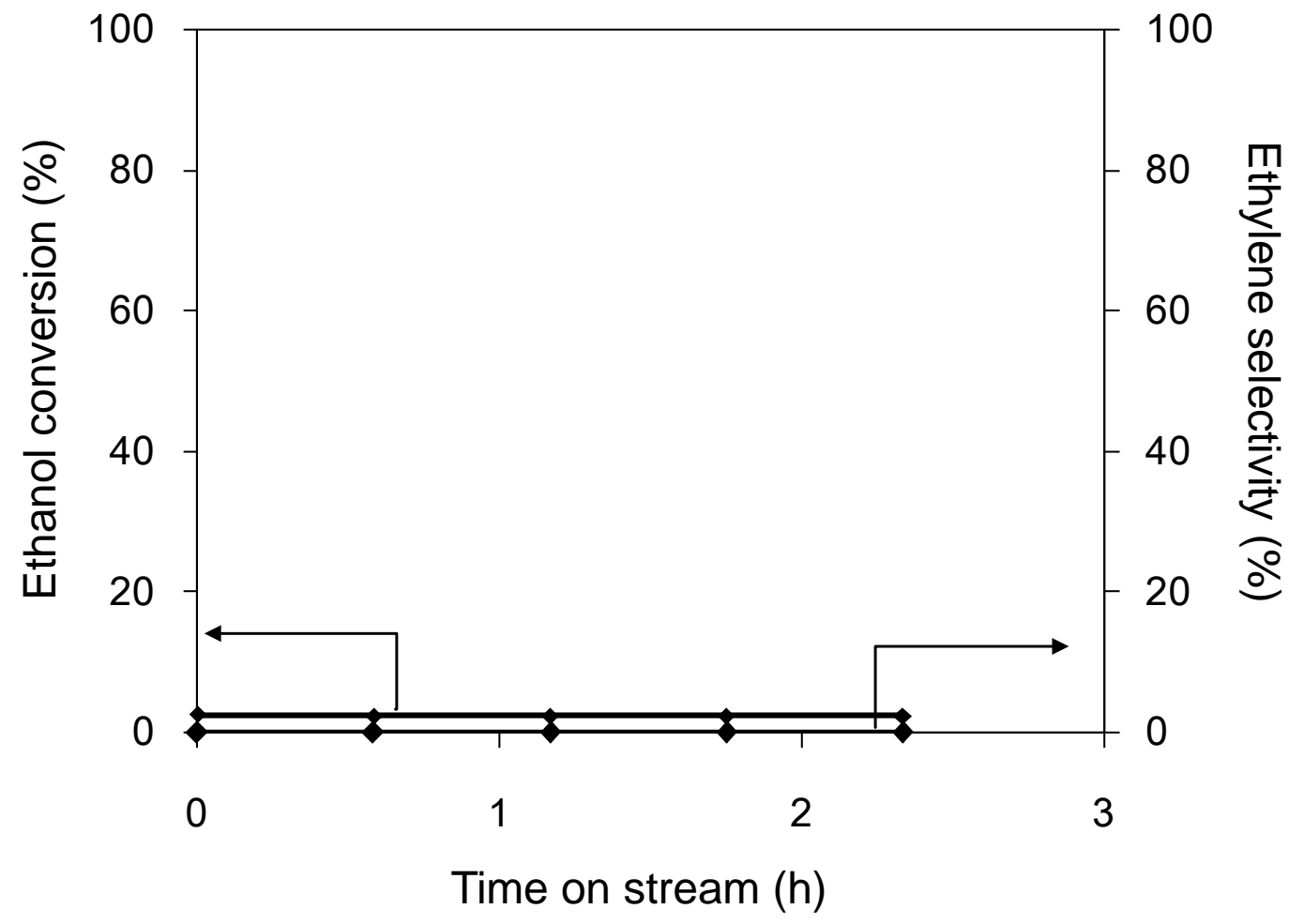

Fig. S6. The ethanol conversion and ethylene selectivity over Silicalite-1. Reaction conditions: $200{ }^{\circ} \mathrm{C}$, ethanol pressure in $\mathrm{He}=19.8 \mathrm{kPa}$, space time $=0.422$ (g of catalyst) $\mathrm{h}$ (g of ethanol) $)^{-1}$. 
SI-6 Stability of the catalysts

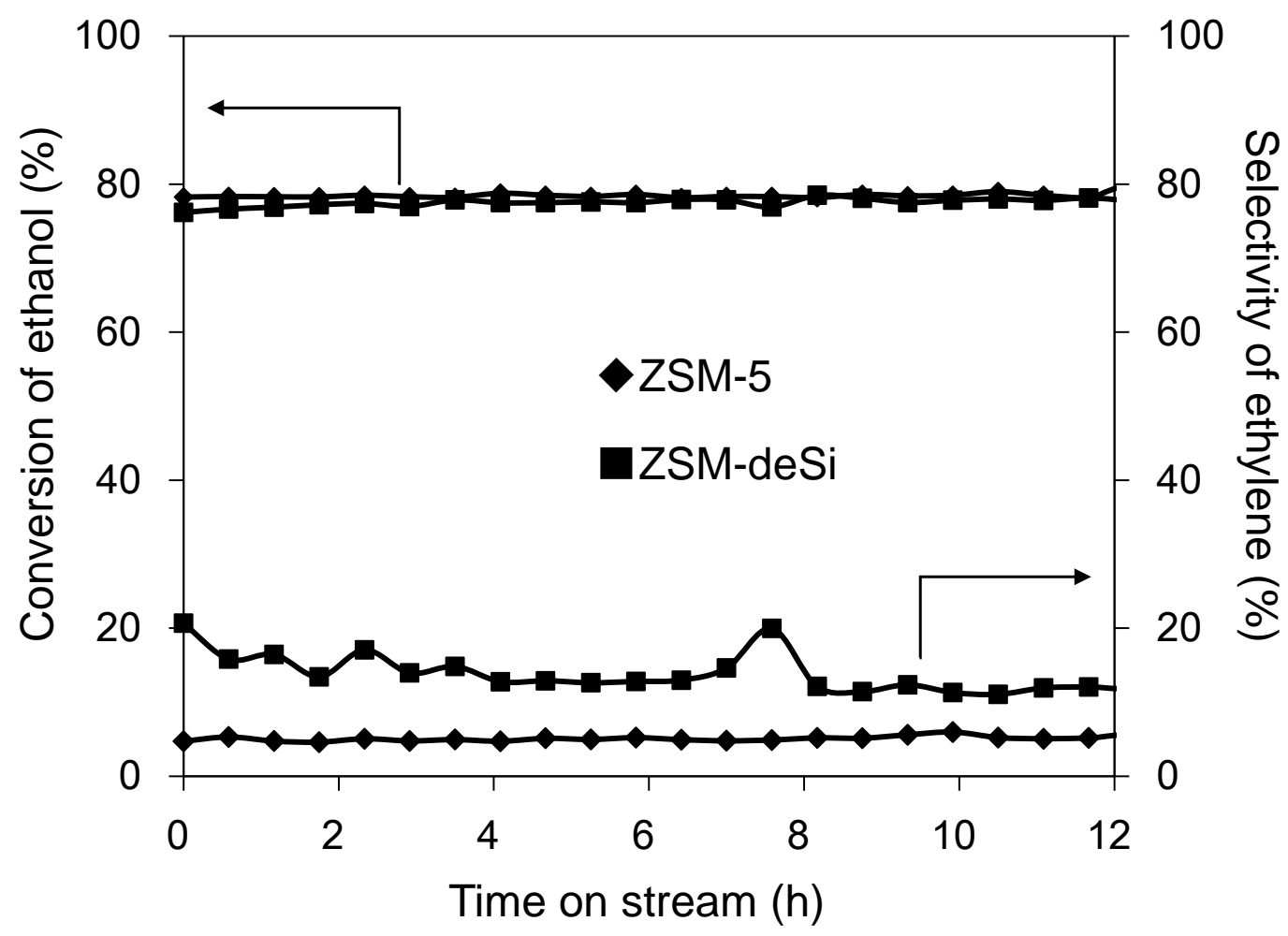

Fig. S7. The conversion of ethanol and selectivity of ethylene over parent and post-treated ZSM-5 catalysts. Reaction conditions: $200{ }^{\circ} \mathrm{C}$, ethanol pressure in $\mathrm{He}=12.6 \mathrm{kPa}$, space time $=0.422$ (g of catalyst) $\mathrm{h}$ (g ethanol) ${ }^{-1}$. 
SI-7 Influence of acid strength on reactivity of ethanol to ethylene and diethyl ether

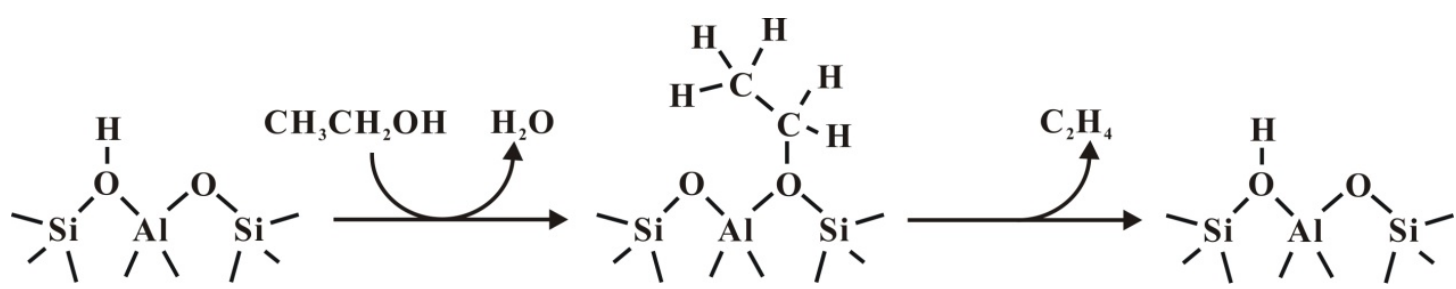

Scheme S1. The reaction mechanism of ethanol-to-ethylene catalyzed by acidic zeolite. 


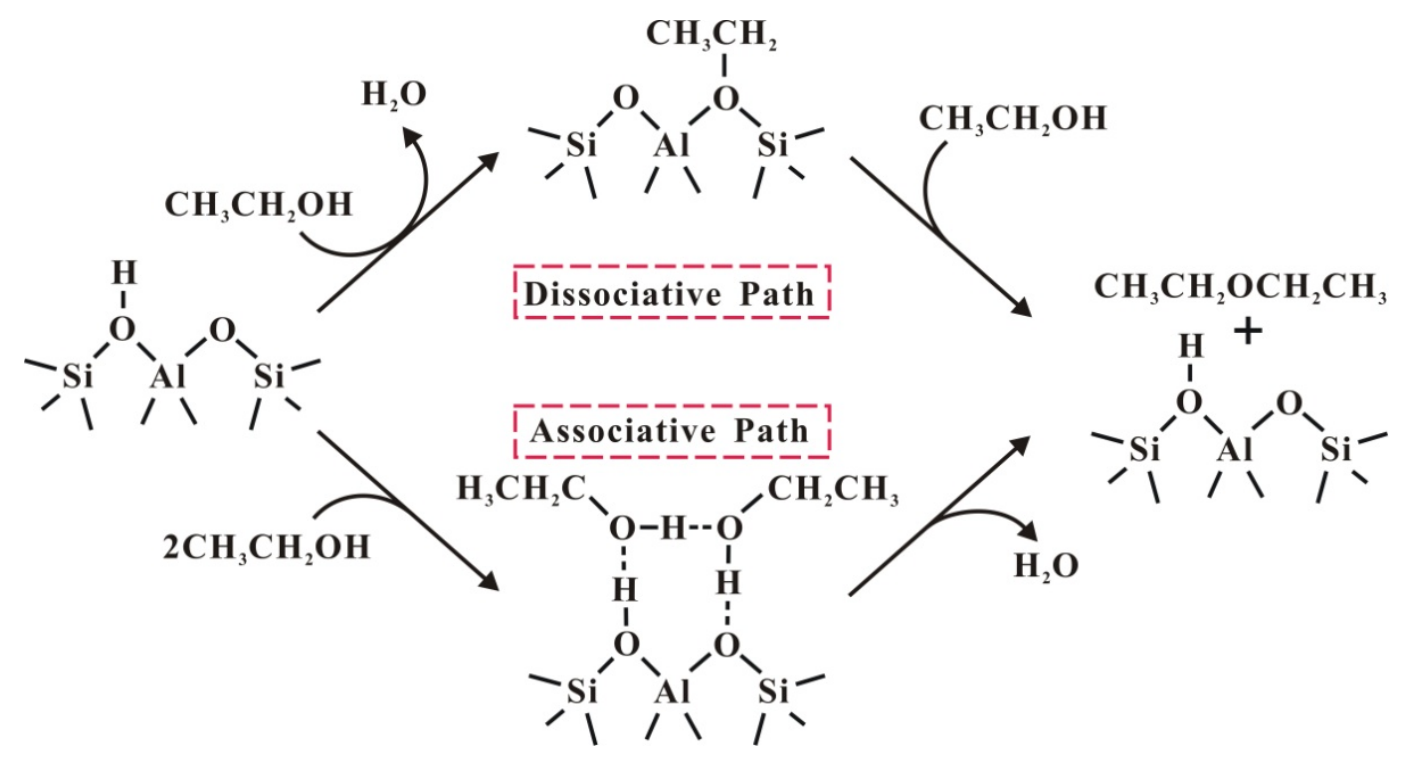

Scheme S2. The dissociative and the associative pathways for the ethanol-to-diethyl ether reaction. 